\title{
Microstructural evolution and mechanical properties of nano-ATZ ceramics by solid solution precipitation
}

\section{Yongdong $\mathrm{Yu}$}

Harbin Institute of Technology

Xudong Liu

Harbin Institute of Technology

\section{Yuchen Yuan}

Harbin Institute of Technology

\section{Wanjun Yu}

Yantai University

\section{Hang Yin}

Harbin Institute of Technology

\section{Zhao Yin}

Harbin Institute of Technology

\section{Y.T. Zheng ( $\nabla$ zhengyt@hit.edu.cn )}

Harbin Institute of Technology https://orcid.org/0000-0001-8509-2132

\section{Xiaodong He}

Harbin Institute of Technology

\section{Research Article}

Keywords: Microstructural evolution, Nano-ATZ, Solid solutions, Nanoprecipitation

Posted Date: June 11th, 2021

DOI: https://doi.org/10.21203/rs.3.rs-607250/v1

License: (c) (1) This work is licensed under a Creative Commons Attribution 4.0 International License. Read Full License

Version of Record: A version of this preprint was published at Journal of Materials Research and Technology on December 1st, 2021. See the published version at https://doi.org/10.1016/j.jmrt.2021.12.057. 


\title{
Microstructural evolution and mechanical properties of nano-ATZ ceramics by solid solution precipitation
}

\author{
Yongdong $\mathrm{Yu}^{1}$, Xudong Liu ${ }^{1}$, Yuchen Yuan ${ }^{1}$, Wanjun $\mathrm{Yu}^{2}$, Hang Yin ${ }^{1}$, Zhao Yin ${ }^{1}$, \\ Yongting Zheng ${ }^{1, *}$, Xiaodong $\mathrm{He}^{1}$ \\ ${ }^{1}$ National Key Laboratory of Science and Technology on Advanced Composites in \\ Special Environments, Center for Composite Materials and Structures, Harbin \\ Institute of Technology, Harbin 150080, P. R. China \\ ${ }^{2}$ School of Environment and Materials Engineering, Yantai University, Yantai \\ 264003, P. R. China \\ *Corresponding author: zhengyt@ hit.edu.cn
}

\begin{abstract}
Alumina toughened zirconia (ATZ) nanoceramics with high-strength, hightoughness and high-hardness were prepared by in-situ nanoprecipitation from solid solution micro-powders. The submicron $\mathrm{Al}_{2} \mathrm{O}_{3}(\sim 450 \mathrm{~nm})$ and $\mathrm{ZrO}_{2}(\sim 350 \mathrm{~nm})$ grains contained low-density precipitated nano- $\mathrm{ZrO}_{2}(\sim 40 \mathrm{~nm})$ and nano- $\mathrm{Y}_{4} \mathrm{Al}_{2} \mathrm{O}_{9}(\mathrm{YAM}, \sim 90$ $\mathrm{nm})$ particles, respectively, making high-performance nano-ATZ ceramics with ultrafine intracrystalline nanostructure yet achieved. There was a parallel or eutectic lattice orientation relationship between the submicrocrystals and its internal nanoparticles of their crystal planes, which is very conducive to the improvement of the mechanical properties of nano-ATZ ceramics. The fracture toughness and hardness of $30 \mathrm{wt} \% \mathrm{Al}_{2} \mathrm{O}_{3} / 70 \mathrm{wt} \% \mathrm{ZrO}_{2}\left(3 \mathrm{~mol}_{2} \mathrm{Y}_{2} \mathrm{O}_{3}\right)$ can be as high as $5.68 \pm 0.17 \mathrm{MPa} \cdot \mathrm{m}^{1 / 2}$ (singleedge V-notched beam method, SEVNB) and $16.32 \pm 0.45 \mathrm{GPa}$, respectively, which are improved by $\sim 25 \%$ and $\sim 20 \%$ compared with those of 3Y-TZP ceramics. Therefore, this method can be used to prepare nano-ATZ ceramics contained ultrafine nanoparticles and uniform distribution of $\mathrm{Al}_{2} \mathrm{O}_{3}$ phases.
\end{abstract}

Keyword: Microstructural evolution; Nano-ATZ; Solid solutions; Nanoprecipitation

\section{Introduction}

$\mathrm{ZrO}_{2}$ ceramics are widely used because of its excellent strength and toughness due to its $\mathrm{t}-\mathrm{m}$ phase transformation and fine microstructure [1-3]. However, $\mathrm{ZrO}_{2}$ is sensitive to hydrothermal aging [4-6], and its hardness [2,7] is lower than that of zirconia toughened alumina (ZTA) [8-9] and $\mathrm{Al}_{2} \mathrm{O}_{3}$ ceramics [10], which limits its use as biomaterials or wear-resistant devices. There have been some works to improve the 
mechanical properties of $\mathrm{ZrO}_{2}$ ceramics through the ATZ method to make them more reliable and stable [6,11-19].

Zhang et al. [6] made $20 \mathrm{wt} \% \mathrm{Al}_{2} \mathrm{O}_{3} / \mathrm{ZrO}_{2}\left(2 \mathrm{~mol}_{2} \mathrm{Y}_{2} \mathrm{O}_{3} / 0.4 \mathrm{~mol} \% \mathrm{La}_{2} \mathrm{O}_{3}\right)$ ceramics with toughness up to $7.1 \mathrm{MPa} \cdot \mathrm{m}^{1 / 2}$ by conventional sintering and improved their aging stability. The hardness and toughness of the ATZ containing $20 \mathrm{wt} \% \mathrm{Al}_{2} \mathrm{O}_{3}$ and $30 \mathrm{wt} \%$ $\mathrm{Al}_{2} \mathrm{O}_{3}$ prepared by Nevarez-Rascon et al. [12-13] were $16.05 \mathrm{GPa}, 7.7 \mathrm{MPa} \cdot \mathrm{m}^{1 / 2}$ and > $13 \mathrm{GPa}, 6.9 \mathrm{MPa} \cdot \mathrm{m}^{1 / 2}$, respectively. The $20 \mathrm{wt} \% \mathrm{Al}_{2} \mathrm{O}_{3} / \mathrm{ZrO}_{2}\left(2.4 \mathrm{~mol} \% \mathrm{Y}_{2} \mathrm{O}_{3}\right)$ ceramics obtained by Govila et al. [18] through the hot isostatic pressing (HIP) had a flexural strength up to $1764 \mathrm{MPa}$. Li et al. [19] prepared $20 \mathrm{wt} \% \mathrm{Al}_{2} \mathrm{O}_{3} / \mathrm{ZrO}_{2}\left(3 \mathrm{~mol} \% \mathrm{Y}_{2} \mathrm{O}_{3}\right)$ ceramics with the flexural strength of $967 \mathrm{MPa}$ and the toughness of $5.27 \mathrm{MPa} \cdot \mathrm{m}^{1 / 2}$ by spark plasma sintering (SPS). Therefore, the hardness of $\mathrm{ZrO}_{2}$ ceramics is greatly improved by these methods. However, fracture toughness of nano-ATZ ceramics is lower than that of 2Y-TZP $\left(12.6 \mathrm{MPa} \cdot \mathrm{m}^{1 / 2}\right)$ and 3Y-TZP $\left(9.3 \mathrm{MPa} \cdot \mathrm{m}^{1 / 2}\right)$ [2], indicating that nano-ATZ ceramics improve their hardness by sacrificing their toughness. Moreover, these nano-ATZ ceramics are mainly obtained by nanopowders, which have many problems such as easy agglomeration of powders, easy abnormal growth of grains during sintering and uneven distribution of $\mathrm{Al}_{2} \mathrm{O}_{3}$ phase. Hence, it is necessary to find a novel way to prepare nano-ATZ ceramics with high-strength, high-toughness and high-hardness.

In this paper, we prepared nano-ATZ ceramics containing $30 \mathrm{wt} \% \mathrm{Al}_{2} \mathrm{O}_{3}$ by a new method of solid solution precipitation from micro-powders. This kind of powder with high-energy state and high supersaturation was obtained by combustion synthesis assisted spray atomization at 10 50 $\mathrm{MPa}$ and rapid water cooling [20-21]. In this method, the melt holding time is long (several minutes), so that the phases are fully fused to each other, and because of the ultra-high cooling rate, the powder has a very high degree of supersaturation [21], making it no longer dependent on the phase diagram [22]. The nano-ATZ ceramics sintered by this method had higher mechanical properties than those sintered by nanopowders, due to its ultrafine nanostructure and uniform distribution of $\mathrm{Al}_{2} \mathrm{O}_{3}$ phase by solid solution precipitation. Moreover, there are a few nanoparticles in $\mathrm{Al}_{2} \mathrm{O}_{3}$ and $\mathrm{ZrO}_{2}$ grains, which exerts the effect of intracrystalline nano-toughening. This kind of microstructure is difficult to be realized by the previous preparation methods of nano-ATZ ceramics [6, 11-19]. More importantly, $\mathrm{ZrO}_{2}$ contained unprecipitated $\mathrm{Al}_{2} \mathrm{O}_{3}$, which may be very beneficial to improve the aging resistance of $\mathrm{ZrO}_{2}$ ceramics. Therefore, this method has far-reaching guiding significance for nano-ATZ ceramics. 


\section{Experimental Procedure}

\subsection{Raw materials and preparation of solid solution powders}

The supersaturated $30 \mathrm{wt} \% \mathrm{Al}_{2} \mathrm{O}_{3}+70 \mathrm{wt} \% \mathrm{ZrO}_{2}\left(3 \mathrm{~mol} \% \mathrm{Y}_{2} \mathrm{O}_{3}\right)$ solid solution powders (named as AZSSP, as shown in Fig. S1) with an average particle size of about $3 \mu \mathrm{m}$ were obtained via combustion synthesis (Equation 1) assisted rapid water cooling (Fig. S2). The specific preparation method was detailed in our previous work [20-21]. This non-equilibrium solidification greatly improves the solid solubility of the two phases, making it no longer dependent on the phase diagram of $\mathrm{Al}_{2} \mathrm{O}_{3} / \mathrm{ZrO}_{2}$ [22] (Fig. S3). The adiabatic temperature and the spray pressure of powder preparation were set to $4000 \mathrm{~K}$ and $20 \mathrm{MPa}$, respectively. The AZSSP was sieved through 200 mesh to obtain coarse and fine powders.

$$
10 \mathrm{Al}+2 \mathrm{Al}\left(\mathrm{NO}_{3}\right)_{3} \rightarrow 6 \mathrm{Al}_{2} \mathrm{O}_{3}+3 \mathrm{~N}_{2} \uparrow
$$

\subsection{Preparation of nano-ATZ ceramics}

The $\mathrm{Al}_{2} \mathrm{O}_{3} / \mathrm{ZrO}_{2}\left(3 \mathrm{~mol} \% \mathrm{Y}_{2} \mathrm{O}_{3}\right)$ nanoceramics were prepared via hot-press sintering (HP) using the fine powders with high energy ball milling for 1 hour and the vacuum hot-press furnace (ZYD-30-80, Jinzhou Aerospace Vacuum Equipment Co., Ltd., China) at the temperature of $1400{ }^{\circ} \mathrm{C}$ (ATZ-1400), $1450{ }^{\circ} \mathrm{C}$ (ATZ-1450) and $1500{ }^{\circ} \mathrm{C}$ (ATZ-1500) and the pressure of $40 \mathrm{MPa}$ for 1 hour.

\subsection{Characterization of AZSSP and ATZ}

The microstructures were characterized with the Helios NanoLab 600i scanning electron microscope (SEM; FEI, USA) and back scattered electron imaging (BSE). The phase analysis was carried out by Empyrean Intelligent X-ray Diffraction Instrument (Panalytical Analytical Instruments Company, Netherlands). Microstructure characterization and super energy spectrum analysis were performed using the Talos F200X (FEI, U.S.) with ChemiSTEM technology (X-FEG and SuperX EDS) operated at $200 \mathrm{kV}$.

The four-point bending method was used to test the flexural strength of specimens $\left(3 \times 4 \times 36 \mathrm{~mm}^{3}\right)$, and the loading rate, span and bending arm length are $0.5 \mathrm{~mm} / \mathrm{min}$, $30 \mathrm{~mm}$ and $10 \mathrm{~mm}$, respectively. The three-point bending method was used to test the fracture toughness of specimens $\left(2 \times 4 \times 22 \mathrm{~mm}^{3}\right)$, and the loading rate and span were $0.05 \mathrm{~mm} / \mathrm{min}$ and $16 \mathrm{~mm}$, respectively. There are two types of fracture toughness samples: single-edge notched beam (SENB) and single-edge V-notched beam (SEVNB). For SENB samples, a diamond saw with a thickness of $0.15 \mathrm{~mm}$ was used to cut the U-notch, and the ratio of notched depth to sample thickness was 0.35 0.6. 
The SEVNB samples used a femtosecond laser (XIP-5/10/30) to quickly cut an ultrasharp V-notch with the tip radius of about $0.6 \mu \mathrm{m}$ on the root of the U-notch. In this paper, five specimens were tested for flexural strength and fracture toughness respectively, and the average value was taken as the final result. The calculation formulas of flexural strength and fracture toughness are shown in Equation 2 (GB/T 6569-2006 / ISO 14704:2000) and Equation 3 (GB/T 23806-2009 / ISO 15732:2003), respectively.

$$
\begin{gathered}
\sigma_{f}=\frac{3 F a}{w h^{2}} \\
K_{I c}=\frac{P L}{h w^{3 / 2}} \times Y\left(\frac{l}{w}\right) \\
Y\left(\frac{l}{h}\right)=\frac{3}{2} \times\left(\frac{l}{h}\right)^{1 / 2} \times \frac{1.99-\frac{l}{h}\left(1-\frac{l}{h}\right)\left[2.15-3.93 \frac{l}{h}+2.7\left(\frac{l}{h}\right)^{2}\right]}{\left(1+2 \frac{l}{h}\right)\left(1-\frac{l}{h}\right)^{3 / 2}} 4
\end{gathered}
$$

where, $\sigma_{f}$ is the flexural strength, $F$ and $P$ are the bending load, $a$ is the bending arm length, $w$ is the width of the sample, $h$ is the thickness of the sample, $K_{I c}$ is the fracture toughness, $L$ is the span, $l$ is the notched depth and $Y(l / h)$ is the form factor (as shown in Equation 4).

The Archimedes drainage method was used to test the relative density of ATZ. The Vickers hardness (Equation 5, GB/T 16534-1996) of the polished ATZ was measured by HVS-30 (Shanghai Shangcai Testing Machine Co., Ltd., China) with the loading force and loading time of $5 \mathrm{Kg}$ and $15 \mathrm{~s}$, respectively. Since $c / a>1.25$ (where $c$ is the distance between the indentation center and the crack tip and $a$ is the half diagonal length of the indentation impression, Fig. S4), Equation 6 [23] was used to calculate the indentation fracture toughness $\left(K_{I c}\right)$ in indentation method (IM). The average values of relative density, Vickers hardness and fracture toughness calculated by indentation were obtained via 5 effective measurements.

$$
\begin{aligned}
H_{V} & =1.8544 \frac{F}{\left(\frac{d_{1}+d_{2}}{2}\right)^{2}} \\
K_{I c} & =0.016\left(\frac{E}{H_{V}}\right)^{\frac{1}{2}} P c^{-\frac{3}{2}}
\end{aligned}
$$


where, $H v$ is the Vickers hardness, $F$ and $P$ are the bending load, $d_{1}$ and $d_{2}$ are the two diagonal lines of the indentation, $E$ is the elastic modulus (approximately $247 \mathrm{GPa}$ ) and $c$ is the distance between the indentation center and the crack tip.

The $\mathrm{t}-\mathrm{m}$ phase transformation of $\mathrm{ZrO}_{2}$ can be estimated by the $\mathrm{t}-\mathrm{ZrO}_{2}(101)$, m$\mathrm{ZrO}_{2}\left(\overline{1}_{11}\right)$ and $\mathrm{m}-\mathrm{ZrO}_{2}(111)$ crystal planes of XRD phase peaks on the surface and fracture for ATZ samples (SENB and SEVNB), as shown in Equations 7, 8 [24].

$$
\begin{gathered}
V_{m}=\frac{1.311 X_{m}}{1+0.311 X_{m}} \\
X_{m}=\frac{I_{m}(\overline{1} 11)+I_{m}(111)}{I_{m}(\overline{1} 11)+I_{t}(101)+I_{m}(111)}
\end{gathered}
$$

where, $V_{m}$ and $I$ represent the volume fraction and integrated intensity of the t-m $\mathrm{ZrO}_{2}$ phases, respectively.

\section{Results and Discussion}

\subsection{The analysis of AZSSP}

Though the X-ray diffraction (XRD) analysis (Fig. 1a), most of the $\mathrm{Al}_{2} \mathrm{O}_{3}$ phase in the AZSSP was dissolved into $\mathrm{ZrO}_{2}$. Therefore, the lattice constant of $3 \mathrm{Y}-\mathrm{ZrO}_{2}$ became smaller because the radius of $\mathrm{Al}^{3+}$ is smaller than that of $\mathrm{Zr}^{4+}$. The $\mathrm{a}=\mathrm{b}=$ $3.6008 \AA$ and $c=5.1793 \AA$ (PDF \#83-0113) of the fine powder became $\mathrm{a}=\mathrm{b}=3.5989$ $\AA$ and $\mathrm{c}=5.1475 \AA$ (see Table 1 for details), respectively, and these values of the coarse powder became $\mathrm{a}=\mathrm{b}=3.5987 \AA$ and $\mathrm{c}=5.1519 \AA$. The fine powder $(6.05 \mathrm{wt} \%)$ contained more $\mathrm{Y}_{4} \mathrm{Al}_{2} \mathrm{O}_{9}$ (YAM) phase than the coarse powder (1.80 wt \%), and the former (18.86 $\mathrm{wt} \%$ ) had more $\mathrm{m}-\mathrm{ZrO}_{2}$ phase than the latter $(4.54 \mathrm{wt} \%)$ in Table 2 (semiquantitative calculation from XRD), because $\mathrm{Y}_{2} \mathrm{O}_{3}$ in the former mainly formed YAM instead of stabilizing the $\mathrm{ZrO}_{2}$ phase. The cooling rate of coarse powder is lower than that of fine powder, so $\alpha-\mathrm{Al}_{2} \mathrm{O}_{3}$ phase appeared in the former, while only $\gamma-\mathrm{Al}_{2} \mathrm{O}_{3}$ existed in the latter (Fig. 1a). The fine powder contained a small amount of precipitated nanospheres, while the coarse powder contained more spheres and a lot of pores, as shown in Fig. 1. This is because large particles of $\mathrm{Al}_{2} \mathrm{O}_{3} / \mathrm{ZrO}_{2}$ melt are ejected from the nozzle, leaving a small amount of gas remaining in the melt to form pores. In addition, the rapidly cooling water enters the melt and vaporizes into water vapor, which also forms holes. These nanospheres are composed of $\mathrm{ZrO}_{2}$-rich solid solution, from the BSE image of Fig. 1d, and they are surrounded by $\mathrm{Al}_{2} \mathrm{O}_{3}$-rich solid solution.

\subsection{The microstructure and mechanical properties of nano-ATZ}


ATZ-1400, ATZ-1450 and ATZ-1500 were successfully obtained by AZSSP after HP. From the BSE images of their surfaces (Fig. 2), the $\mathrm{Al}_{2} \mathrm{O}_{3}$ phase was evenly distributed among the $\mathrm{ZrO}_{2}$ grains. As the temperature increased, the grain size of $\mathrm{Al}_{2} \mathrm{O}_{3}$ gradually became larger. ATZ-1500 had abnormally grown $\mathrm{Al}_{2} \mathrm{O}_{3}$ grains with a size of 1-2 $\mu \mathrm{m}$. The average grain sizes of $\mathrm{ZrO}_{2}$ and $\mathrm{Al}_{2} \mathrm{O}_{3}$ are $350 \mathrm{~nm}$ and $450 \mathrm{~nm}$, respectively, from the TEM and STEM images of ATZ-1450 (Fig. 3, Fig. 4 and Fig. S5). The $\mathrm{Al}_{2} \mathrm{O}_{3}$ crystal contains a small amount of nano- $\mathrm{ZrO}_{2}$ particles with diameter of $\sim 40 \mathrm{~nm}$, and the $\mathrm{ZrO}_{2}$ crystal also contains nano-YAM particles (see Fig. $7 \mathrm{~b}$ for detailed analysis) with diameter of $\sim 90 \mathrm{~nm}$. This ultrafine structure will be very beneficial to improve the properties of nano-ATZ ceramics.

The STEM-EDX mapping and line scan analysis of ATZ-1450 in Fig. 5 and Fig. 6 show that a small amount of $\mathrm{Al}_{2} \mathrm{O}_{3}$ was not precipitated from $\mathrm{ZrO}_{2}$. The unprecipitated $\mathrm{Al}_{2} \mathrm{O}_{3}$ acts as a stabilizer and inhibits the $\mathrm{t}-\mathrm{m}$ phase transformation of $\mathrm{ZrO}_{2}$, which may be very beneficial to the hydrothermal aging resistance of Y-TZP. The precipitated $\mathrm{Al}_{2} \mathrm{O}_{3}$ and the $\gamma-\mathrm{Al}_{2} \mathrm{O}_{3}$ in the AZSSP finally exist in the ceramic as the $\alpha$-phase at hightemperature [21]. This was also confirmed by the selected area electron diffraction (SAED) of $\mathrm{Al}_{2} \mathrm{O}_{3}$ in area $\mathrm{A}$, as shown in Fig. 5a, 5b. The $\mathrm{ZrO}_{2}$ existed in the form of $\mathrm{m}$ - and t-phase from the SAED of $\mathrm{ZrO}_{2}$ grains in area $\mathrm{B}$ and $\mathrm{C}$ (Fig. 5c, 5d). At the same time, $\mathrm{t}-\mathrm{ZrO}_{2}$ had a superlattice structure due to the presence of $\mathrm{Y}_{2} \mathrm{O}_{3}$ and incompletely precipitated $\mathrm{Al}_{2} \mathrm{O}_{3}$. The nanocrystals inside $\mathrm{Al}_{2} \mathrm{O}_{3}$ and $\mathrm{ZrO}_{2}$ were further studied by high resolution transmission electron microscope (HRTEM) and fast Fourier transform (FFT) in Fig. 7. The nanocrystals in the $\mathrm{ZrO}_{2}$ are YAM (Fig. 7a, area I), and there is an orientation relationship of (111)m- $\mathrm{ZrO}_{2} / /(222) Y A M$. Similarly, the nanocrystals in the $\mathrm{Al}_{2} \mathrm{O}_{3}$ are $\mathrm{ZrO}_{2}$ (Fig. 7b, area I). However, due to the presence of $\mathrm{Y}_{2} \mathrm{O}_{3}$ stabilizers in $\mathrm{ZrO}_{2}$, the area around the nano- $\mathrm{ZrO}_{2}$ particles is YAP (Fig. 7b, area II), and these two phases form the eutectic lattice orientation relationship. Therefore, there is a small amount of YAP around the $\mathrm{ZrO}_{2}$ nanoparticles in $\mathrm{Al}_{2} \mathrm{O}_{3}$ crystals. These unique structures are very helpful to improve the performance of ceramics.

The nano-ATZ ceramics prepared via this novel method had excellent mechanical properties. Their flexural strength $(\sigma)$ and hardness $\left(H_{v}\right)$ can be as high as $896 \pm 58$ $\mathrm{MPa}$ and $16.32 \pm 0.45 \mathrm{GPa}$, respectively, as shown in Table 3. The flexural strength is similar to that of $3 \mathrm{Y}-\mathrm{TZP}$ and ATZ ceramics $[2,12]$ but the hardness is increased by about $20 \%$. In order to accurately measure the fracture toughness of nano-ATZ ceramics, IM, SENB and SEVNB are used respectively. The U-notched root radius of the SENB specimen is about $100 \mu \mathrm{m}$ (Fig. 8a), and the fracture toughness is greatly 
overestimated [25]. Many studies [25-27] have shown that using a femtosecond laser to cut an ultra-sharp V-notch at the root of the U-notch (the SEVNB method) can be used to characterize the toughness of ceramics. When the $\mathrm{V}$-notched tip radius is less than 1.5 to 3 times of the grain size [27-29], the fracture toughness of the ceramic can be accurately measured. The V-notched tip radius of nano-ATZ ceramics is $\sim 0.6 \mu \mathrm{m}$ (Fig. 8b, 8c), which is much smaller than three times of their grain size, so the SEVNB method can accurately measure their fracture toughness. In addition, many studies [3031] have shown that when the U-notched root radius is less than the depth of the Vnotch, and the equivalent notch angle is less than $60^{\circ}$ (as shown in Fig. 9a), the SEVNB method can truly measure the fracture toughness accurately. The U-notched root radius $(r)$, the $\mathrm{V}$-notched depth $(l)$ and the equivalent notch angle $(\theta)$ of SEVNB samples for nano-ATZ ceramics are about $104 \mu \mathrm{m}, 165 \mu \mathrm{m}$ and $45^{\circ}$ (as shown in Fig. 9b), respectively. The $r / l \approx 0.63<1$ and $45^{\circ}<60^{\circ}$, so SEVNB samples meet test standards and can accurately measure the their fracture toughness. The fracture toughness of the ATZ-1450 sample was as high as $5.68 \pm 0.17 \mathrm{MPa} \cdot \mathrm{m}^{1 / 2}$ (SEVNB), which was much lower than the measured values of IM $\left(6.97 \pm 0.24 \mathrm{MPa} \cdot \mathrm{m}^{1 / 2}\right)$ and SENB $(13.31 \pm 0.45$ $\mathrm{MPa} \cdot \mathrm{m}^{1 / 2}$ ), as shown in Table 4 . The test results of the ATZ-1400 and ATZ-1500 were also the same as that of ATZ-1450. Compared with SEVNB, the fracture toughness of IM and SENB were overestimated by $\sim 26.99 \%$ and $\sim 138.40 \%$, respectively, as shown in Table 5. The difference between SENB and SEVNB methods can be seen from their typical stress-displacement curves (Fig. 10a). For the SEVNB specimen (Fig. 10b), the $\mathrm{V}$-notched tip provides the source of cracks. When the external loading reaches $F_{0}$, the crack tip expands steadily and the stress begins to release at the crack tip, so the stressdisplacement curve shows a smooth nonlinear change. Because $\mathrm{ZrO}_{2}$ ceramics contains $\mathrm{t}-\mathrm{m}$ phase transition, it has strong resistance to crack extension, so crack propagation can be seen in the stress-displacement curve of SEVNB. The crack expands steadily up to the maximum load $\left(F_{\max }\right)$ and then grows instability, and eventually the specimen fractures at the load of $F^{*}$. For SENB specimens (Fig. 10c), the bottom of the smooth U-notch cannot provide the source of cracks. When the external load increases to a certain value, crack induction, crack propagation and fracture occur simultaneously. Because the load required to induce a microcrack is much greater than that for crack propagation and specimen fracture, the fracture toughness measured by the SENB method is overestimated. The SENB sample has no crack propagation, leading to direct fracture of the sample, so the stress-displacement curve has no deflection (Fig. 10c). 
Therefore, the SEVNB method can accurately measure the ceramic toughness of resistance to crack propagation.

The fracture surface morphology of nano-ATZ ceramics, as shown in Fig. 11, can further show the reasons for the high strength and high toughness of ceramics prepared by this method. The fracture surfaces of the ATZ-1400, ATZ-1450 and ATZ-1500 specimens are uneven (Fig. 11a, 11b, 11c), and there are a lot of crack deflection and crack bifurcation (Fig. 11d, 11e, 11f), which greatly increases the crack growth path and improves the strength and toughness of ceramics. The high-magnification BSE and SEM images (Fig. 12) of the fracture surface for ATZ-1400, ATZ-1450 and ATZ-1500 show that nano-ATZ ceramics mainly occur intergranular fracture, and $\mathrm{Al}_{2} \mathrm{O}_{3}$ phases are evenly distributed in the $\mathrm{ZrO}_{2}$ matrix. The ATZ-1400 fracture surface (Fig. 12a, $12 \mathrm{~b}$ ) contains a lot of microcrack toughening, especially the evenly distributed $\mathrm{Al}_{2} \mathrm{O}_{3}$ phase deflects the cracks (pointed by red arrows in Fig. 12b), which is very beneficial to improve the toughness of ceramics. In addition, some $\mathrm{ZrO}_{2}$ phases undergo transgranular fracture (pointed by green arrows in Fig. 12b), which makes the t-m phase transition as high as $9.72 \%$ (SENB, as shown in Fig. 13 and Table 4) and $6.04 \%$ (SEVNB), so its fracture toughness is as high as $5.53 \pm 0.15 \mathrm{MPa} \cdot \mathrm{m}^{1 / 2}(\mathrm{SEVNB})$, which is higher than that of $3 \mathrm{Y}-\mathrm{TZP}\left(4.4 \mathrm{MPa} \cdot \mathrm{m}^{1 / 2}, \mathrm{SEVNB}\right)$ and increased by about $25 \%$ [27]. The fracture morphology of ATZ-1450 is similar to that of ATZ-1400, and there are also microcrack propagation and crack deflection toughening (pointed by red arrows in Fig. 12d and Fig. 14). The difference is that there are some particles pulled out (pointed by blue arrows in Fig. 12d), which greatly increases the toughness of ceramics. The cross-sectional STEM image (Fig. 14) of microcrack growth in ATZ-1450 provides a more visual representation of the toughening mechanism. The uniformly distributed $\mathrm{Al}_{2} \mathrm{O}_{3}$ phase causes intergranular or transgranular fracture to promote crack deflection, as shown in red and green arrows, respectively. Similarly, some $\mathrm{ZrO}_{2}$ phases undergo transgranular fracture (pointed by blue arrows in Fig. 14), which makes the t-m phase transition as high as $10.58 \%$ (SENB, as shown in Fig. 13 and Table 4) and $4.47 \%$ (SEVNB). At the same time, the YAM in the $\mathrm{ZrO}_{2}$ crystal makes the crack deflection again, as shown in the dashed area in Fig. 14. Furthermore, YAM and $\mathrm{ZrO}_{2}$ have a unique orientation relationship (Fig. 7a), so transgranular fracture of $\mathrm{ZrO}_{2}$ consumes a lot of energy, thereby greatly improving the fracture toughness of ceramics. ATZ-1500 also mainly occurs intergranular fracture (Fig. 12e, 12f), and the grain size is significantly larger than that of ATZ-1400 and ATZ-1450. Like ATZ-1450, ATZ-1500 also has particle pull-out toughening, as shown in blue arrows in Fig. 12f. In addition, 
the large-size grains of ATZ-1500 contain a lot of small particles on the grain boundary (Fig. 12f), which greatly increases its crack propagation path, thereby improving the toughness of ceramics. The $\mathrm{t}-\mathrm{m}$ phase transition of ATZ-1500 is as high as $13.45 \%$ (SENB) and $3.15 \%$ (SEVNB), as shown in Fig. 13 and Table 4. Therefore, nano-ATZ ceramics prepared by solid solution nanoprecipitation have ultra-fine microstructure and high mechanical properties.

\section{Conclusion}

In summary, nano-ATZ nanoceramics were successfully prepared via the solid solution nanoprecipitation. The submicron-sized $\mathrm{ZrO}_{2}$ and $\mathrm{Al}_{2} \mathrm{O}_{3}$ grains contain nanosized YAM and $\mathrm{ZrO}_{2}$ particles, respectively. The flexural strength, fracture toughness and hardness of nano-ATZ can be as high as $896 \pm 58 \mathrm{MPa}, 5.68 \pm 0.17 \mathrm{MPa} \cdot \mathrm{m}^{1 / 2}$ (SEVNB) and 16.32 $\pm 0.45 \mathrm{GPa}$, respectively, because of the ultrafine structure by insitu nanoprecipitation. Therefore, this method has important guiding significance for nano-ATZ ceramics with high-performance.

\section{Data availability}

Raw data were generated at Harbin Institute of Technology, China. Derived data supporting the findings of this study are available from the corresponding author $\mathrm{YZ}$ on request.

\section{CRediT authorship contribution statement}

Yongdong Yu: Conceptualization, Methodology, Data curation, Writing - original draft. Xudong Liu: Formal analysis. Yuchen Yuan: Conceptualization. Wanjun Yu: Methodology, Resources. Hang Yin: Conceptualization. Zhao Yin: Formal analysis. Yongting Zheng: Writing - review \& editing, Funding acquisition, Validation. Xiaodong He: Supervision, Validation, Investigation.

\section{Declaration of Competing Interest}

The authors declare that they have no known competing financial interests or personal relationships that could have appeared to influence the work reported in this paper.

\section{Acknowledgements}

This work was supported by the National Natural Science Foundation of China (Grant No. 91016014 and 51872062). We thank Harbin Jehot Advanced Materials Co., Ltd. (China) for help with the powder preparation. 


\section{References}

[1] Hannink RH, Kelly PM, Muddle BC. Transformation toughening in zirconiacontaining ceramics. J Am Ceram Soc 2000, 83: 461-487.

[2] Vasylkiv O, Sakka Y, Skorokhod VV. Low-temperature processing and mechanical properties of zirconia and zirconia-alumina nanoceramics. $J$ Am Ceram Soc 2003, 86: 299-304.

[3] Travitzky N, Bonet A, Dermeik B, et al. Additive manufacturing of ceramic-based materials. Adv Eng Mater 2014, 16: 729-754.

[4] Zhang F, Vanmeensel K, Inokoshi M, et al. Critical influence of alumina content on the low temperature degradation of 2-3 mol\% yttria-stabilized TZP for dental restorations. J Eur Ceram Soc 2015, 35: 741-750.

[5] Lughi V, Sergo V. Low temperature degradation-aging-of zirconia: A critical review of the relevant aspects in dentistry. Dent Mater 2010, 26: 807-820.

[6] Zhang F, Chevalier J, Olagnon C, et al. Slow crack growth and hydrothermal aging stability of an alumina-toughened zirconia composite made from $\mathrm{La}_{2} \mathrm{O}_{3}$-doped 2Y-TZP. J Eur Ceram Soc 2017, 37: 1865-1871.

[7] Gogotsi GA. Fracture toughness of ceramics and ceramic composites. Ceram Int 2003, 29: 777-784.

[8] Zhan GD, Kuntz J, Wan J, et al. A novel processing route to develop a dense nanocrystalline alumina matrix $(<100 \mathrm{~nm})$ nanocomposite material. J Am Ceram Soc 2003, 86: 200-2002.

[9] Yu Y, Zheng Y, Yu W, et al. Evolution of interfacial microstructures between tungsten wires/flakes or graphite flakes and $\mathrm{Al}_{2} \mathrm{O}_{3} / \mathrm{ZrO}_{2}$ eutectic ceramics via a novel combustion synthesis centrifugal casting. Ceram Int 2019, 45: 14742-14748.

[10] Riu DH, Kong YM, Kim HE. Effect of $\mathrm{Cr}_{2} \mathrm{O}_{3}$ addition on microstructural evolution and mechanical properties of $\mathrm{Al}_{2} \mathrm{O}_{3}$. J Eur Ceram Soc 2000, 20: 1475 1481.

[11] Schneider J, Begand S, Kriegel R, et al. Low-temperature aging behavior of alumina-toughened zirconia. J Am Ceram Soc 2008, 91: 3613-3618.

[12] Borunda EO, Elguezabal AA. $\mathrm{Al}_{2} \mathrm{O}_{3}(\mathrm{w})-\mathrm{Al}_{2} \mathrm{O}_{3}(\mathrm{n})-\mathrm{ZrO}_{2}(\mathrm{TZ}-3 \mathrm{Y}) \mathrm{n}$ multi-scale nanocomposite: An alternative for different dental applications? Acta Biomater 2010, 6: 563-570.

[13] Nevarez-Rascon A, Aguilar-Elguezabal A, Orrantia E, et al. On the wide range of mechanical properties of ZTA and ATZ based dental ceramic composites by 
varying the $\mathrm{Al}_{2} \mathrm{O}_{3}$ and $\mathrm{ZrO}_{2}$ content. Int J Refract Met Hard Mater 2009, 27: 962 970.

[14] Borlaf M, Szubra N, Serra-Capdevila A, et al. Fabrication of $\mathrm{ZrO}_{2}$ and ATZ materials via UV-LCM-DLP additive manufacturing technology. J Eur Ceram Soc 2020, 40: 1574-1581.

[15] Verga F, Borlaf M, Conti L, et al. Laser-based powder bed fusion of alumina toughened zirconia. Addit Manuf 2020, 31: 100959.

[16] Ai Y, Xie X, He W, et al. Microstructure and properties of $\mathrm{Al}_{2} \mathrm{O}_{3}(\mathrm{n}) / \mathrm{ZrO}_{2}$ dental ceramics prepared by two-step microwave sintering. Mater Des 2015, 65: 10211027.

[17] Nevarez-Rascon A, Aguilar-Elguezabal A, Orrantia E, et al. Compressive strength, hardness and fracture toughness of $\mathrm{Al}_{2} \mathrm{O}_{3}$ whiskers reinforced ZTA and ATZ nanocomposites: Weibull analysis. Int J Refract Met Hard Mater 2011, 29: 333340.

[18] Govila R. Strength characterization of yttria-partially stabilized zirconia/alumina composite. J Mater Sci 1993, 28: 700-718.

[19] Li S, Izui H, Okano M, et al. Microstructure and mechanical properties of $\mathrm{ZrO}_{2}$ $\left(\mathrm{Y}_{2} \mathrm{O}_{3}\right)-\mathrm{Al}_{2} \mathrm{O}_{3}$ nanocomposites prepared by spark plasma sintering. Particuology 2012, 10: 345-351.

[20] Yu Y, Lin F, Zheng Y, et al. High-density nanoprecipitation mechanism and microstructure evolution of high-performance $\mathrm{Al}_{2} \mathrm{O}_{3} / \mathrm{ZrO}_{2}$ nanocomposite ceramics. J Eur Ceram Soc 2021, 41: 5269-5279.

[21] $\mathrm{Yu}$ Y, Zheng Y, Liu X, et al. Microstructure evolution of $\mathrm{YSZ} / \mathrm{Al}_{2} \mathrm{O}_{3}$ supersaturated solid solution, Appl Surf Sci 2021, 549: 149260.

[22] ALPER AM. Science of ceramics, ed. G. H. Stewart, Academic Press, London, $1967,339$.

[23] Anstis GR, Chantikul P, Lawn BR, et al. A critical evaluation of indentation techniques for measuring fracture toughness: I, direct crack measurements. $J$ Am Ceram Soc 1981, 64: 533-538.

[24] Toraya H, Yoshimura M, Somiya S. Calibration curve for quantitative analysis of the monoclinic-tetragonal $\mathrm{ZrO}_{2}$ system by x-ray diffraction. J Am Ceram Soc 1984, 67: 119-121.

[25] Zhao W, Cui J, Rao P. Effect of molten zone ablated by femtosecond lasers on fracture toughness of $\mathrm{Si}_{3} \mathrm{~N}_{4}$ measured by SEVNB method. J Eur Ceram Soc 2018, 38: 2243-2246. 
[26] Turon-Vinas M, Anglada M. Fracture toughness of zirconia from a shallow notch produced by ultra-short pulsed laser ablation. J Eur Ceram Soc 2014, 34: 38653870.

[27] Cui J, Gong Z, Rao P. Effect of molten zone ablated by femtosecond laser on fracture toughness of oxide ceramics. J Eur Ceram Soc 2017, 38: 2440-2444.

[28] Nishida T, Hanaki Y, Pezzotti G. Effect of notch-root radius on the fracture toughness of a fine-grained alumina. J Am Ceram Soc 1994, 77: 606-608.

[29] Yang S, Zhang C, Zhang X. Notch radius effect on fracture toughness of ceramics pertinent to grain size. J Eur Ceram Soc 2020, 40: 4217-4223.

[30] Wang X, Atkinson A. On the measurement of ceramic fracture toughness using single edge notched beams. J Eur Ceram Soc 2015, 35: 3713-3720.

[31] Wang A, Du B, Hu P, et al. Reliable evaluation of fracture toughness in ceramics via nanosecond laser notching method. J Eur Ceram Soc 2019, 39: 883-889. 


\section{Figure captions:}

Fig. 1 (a) XRD patterns of AZSSP. The BSE images of cross-sections of fine powders (b) and coarse powders (c). (d) An enlarged view of the box area in Fig. (c). The light phase represents the $\mathrm{ZrO}_{2}$ phase, and the dark phase represents the $\mathrm{Al}_{2} \mathrm{O}_{3}$ phase.

Fig. 2 The cross-sectional BSE pictures of ATZ-1400, ATZ-1450 and ATZ-1500. The bright phase and the dark phase represent the $\mathrm{ZrO}_{2}$ phase and the $\mathrm{Al}_{2} \mathrm{O}_{3}$ phase, respectively.

Fig. 3 Cross-sectional TEM (a) and STEM (b) images of ATZ-1450. The bright phase and the dark phase in Fig. (b) represent the $\mathrm{ZrO}_{2}$ phase and the $\mathrm{Al}_{2} \mathrm{O}_{3}$ phase, respectively.

Fig. 4 The size distribution of nano- $\mathrm{ZrO}_{2}$ grains in the $\mathrm{Al}_{2} \mathrm{O}_{3}$ grains (a), nano- $\mathrm{Y}_{4} \mathrm{Al}_{2} \mathrm{O}_{9}$ grains in the $\mathrm{ZrO}_{2}$ grains (b), submicro- $\mathrm{ZrO}_{2}$ grains (c) and submicro- $\mathrm{Al}_{2} \mathrm{O}_{3}$ grains (d) in Fig. 3(b). The average grain size of these four grains is about $40 \mathrm{~nm}, 90 \mathrm{~nm}, 350 \mathrm{~nm}$ and $450 \mathrm{~nm}$, respectively.

Fig. 5 (a) Cross-sectional STEM image of ATZ-1450. (b), (c) and (d) images show the selected area electron diffraction (SAED) of regions A, B, and C in Fig. (a). (e), (f), (g) and (h): The STEM-EDX elemental mappings show the distribution of $\mathrm{Al}, \mathrm{O}, \mathrm{Zr}$ and $\mathrm{Y}$ elements, respectively.

Fig. 6 (a) STEM image of ATZ-1450. (b) The STEM-EDX composition profile at the arrow position in Fig. (a) shows the distribution of $\mathrm{Al}, \mathrm{O}, \mathrm{Zr}$ and $\mathrm{Y}$ elements, respectively.

Fig. 7 HRTEM images of nanoparticles inside $\mathrm{ZrO}_{2}$ crystal (a) and $\mathrm{Al}_{2} \mathrm{O}_{3}$ crystal (b). I, II and III are enlarged images of different regions in Fig. (a) and Fig. (b), respectively. Insets in I and II are the corresponding FFT patterns.

Fig. 8 (a) The SEM image of SENB sample showing that the root radius of U-notch is about $100 \mu \mathrm{m}$. (b) The SEM image of SEVNB sample showing that a femtosecond laser is used to cut an ultra-sharp V-notch based on the U-notch. (c) An enlarged view of the $\mathrm{V}$-notch with the tip radius of $\sim 0.6 \mu \mathrm{m}$ (much less than three times the grain size of ceramics [27-29]) indicating that this method can accurately measure the fracture toughness of ceramics.

Fig. 9 (a) Schematic of the ultra-sharp V-notch with an equivalent notch angle $(\theta)$. The $\theta$ should be less than $60^{\circ}$ and the U-notched root radius $(r)$ should be less than the $\mathrm{V}$ notched depth $(l)$. (b) The SEM image of ceramic bar with an ultra-sharp V-notch based on the U-notch. The U-notched root radius $(r)$, the V-notched depth $(l)$ and the equivalent notch angle $(\theta)$ of SEVNB samples are about $104 \mu \mathrm{m}, 165 \mu \mathrm{m}$ and $45^{\circ}$, respectively. $r / l \approx 0.63<1$ and $45^{\circ}<60^{\circ}$, so SEVNB samples meet test standards. 
Fig. 10 (a) Stress-displacement graphs of SENB and SEVNB specimens. (b)and (c) are enlarged images of the dotted area in Fig. (a).

Fig. 11 The SEM images of fracture surface in the ATZ-1400 (a), ATZ-1450 (b) and ATZ-1500 (c). (d), (e) and (f) are the enlarged images of the dashed area in Figs. (a), (b) and (c).

Fig. 12 (a) and (b): The BSE images of fracture surface in the ATZ-1400. (c) and (d): The SEM images of fracture surface in the ATZ-1450. (e) and (f): The SEM images of fracture surface in the ATZ-1500.

Fig. 13 The XRD analysis of $(101) \mathrm{t},(\overline{1} 11)_{\mathrm{m}}$ and $(111)_{\mathrm{m}}$ crystal planes on fracture and surface of SENB (a) and SEVNB (b) samples.

Fig. 14 (a) Cross-sectional STEM image of microcrack growth in ATZ-1450. The red and green arrows show green intergranular and transgranular fracture of $\mathrm{Al}_{2} \mathrm{O}_{3}$ grains, respectively. The blue arrows represent the transcrystalline fracture of $\mathrm{ZrO}_{2}$, and the circled areas indicate that the nanoparticles inside the $\mathrm{ZrO}_{2}$ grains promote crack deflection. 

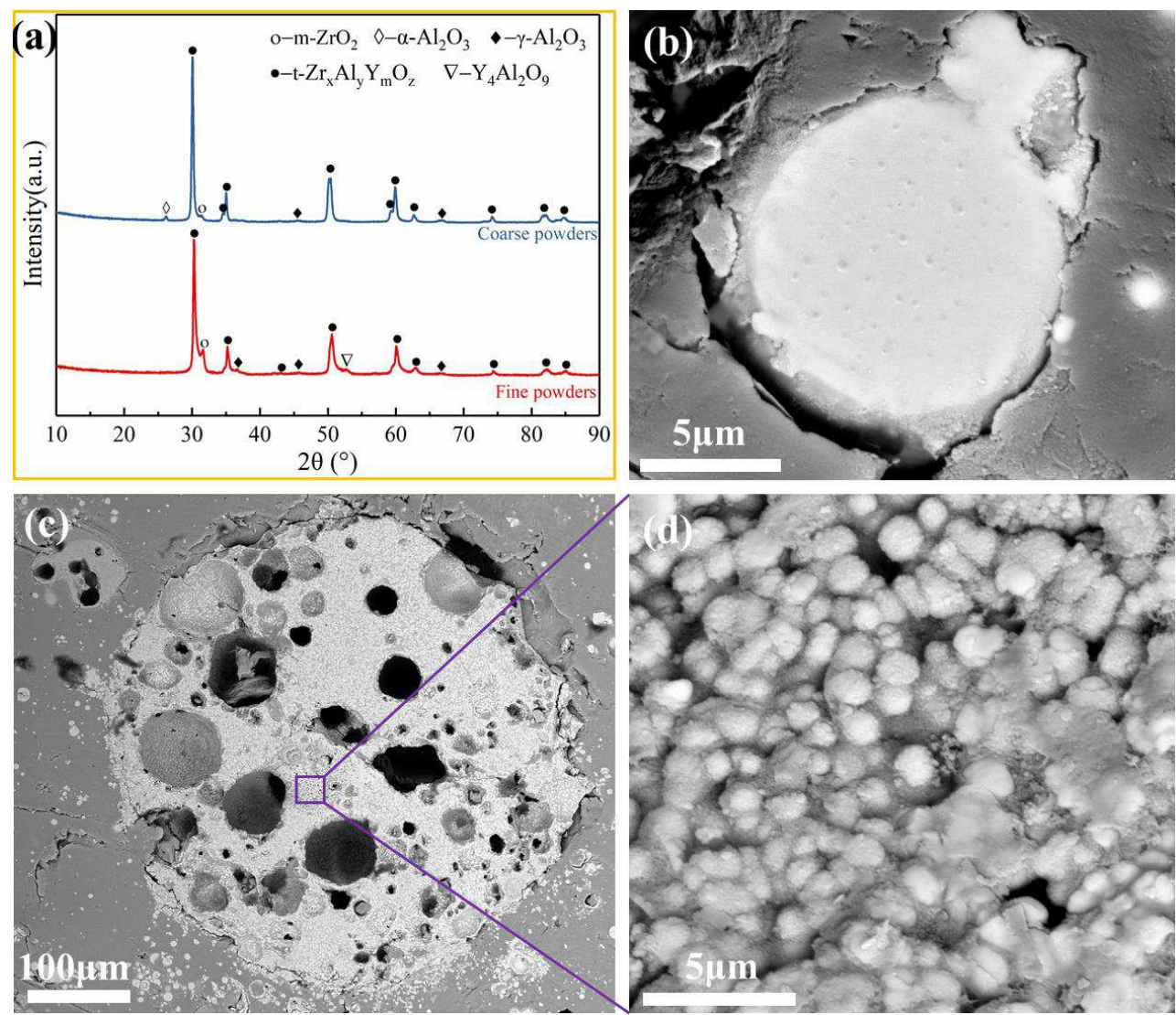

Fig. 1 (a) XRD patterns of AZSSP. The BSE images of cross-sections of fine powders (b) and coarse powders (c). (d) An enlarged view of the box area in Fig. (c). The light phase represents the $\mathrm{ZrO}_{2}$ phase, and the dark phase represents the $\mathrm{Al}_{2} \mathrm{O}_{3}$ phase.

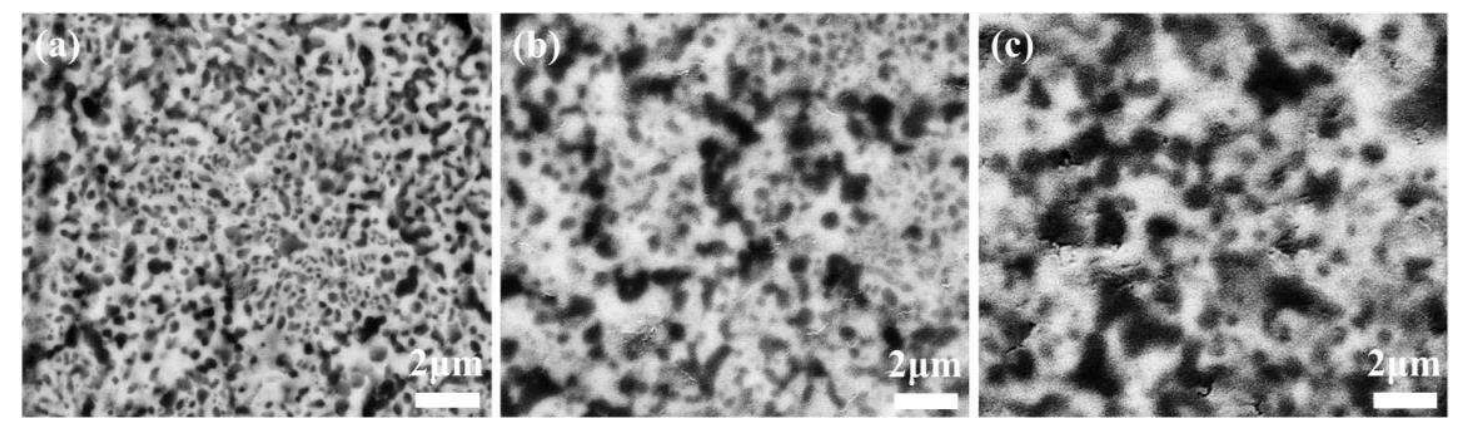

Fig. 2 The cross-sectional BSE pictures of ATZ-1400, ATZ-1450 and ATZ-1500. The bright phase and the dark phase represent the $\mathrm{ZrO}_{2}$ phase and the $\mathrm{Al}_{2} \mathrm{O}_{3}$ phase, respectively. 

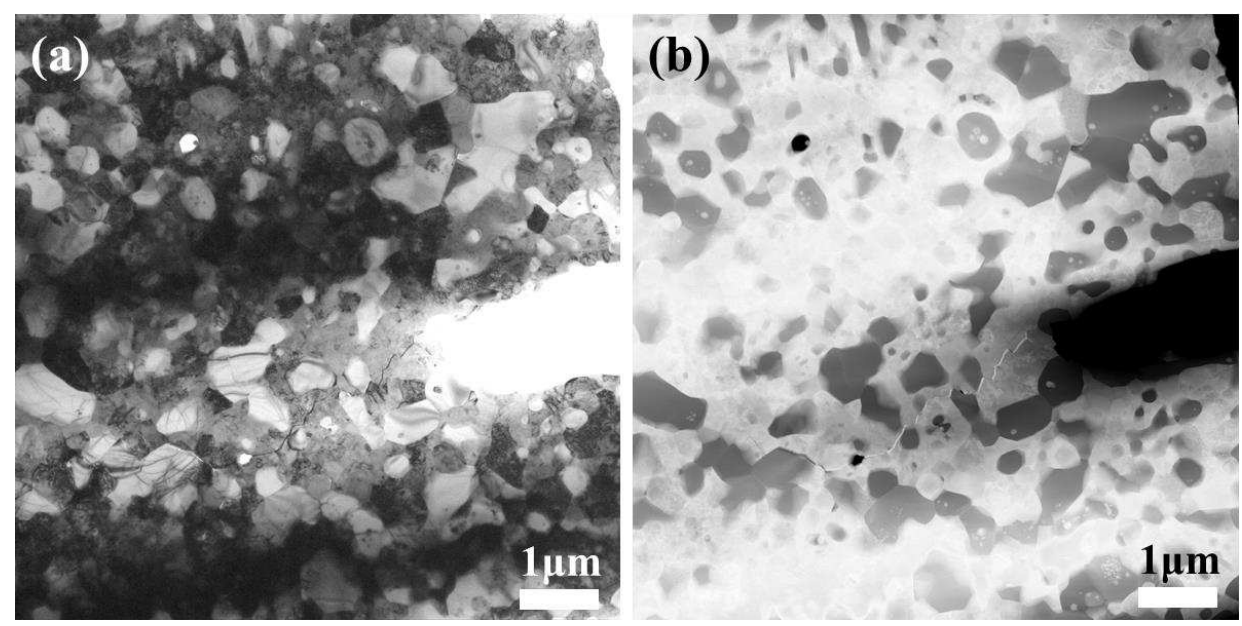

Fig. 3 Cross-sectional TEM (a) and STEM (b) images of ATZ-1450. The bright phase and the dark phase in Fig. (b) represent the $\mathrm{ZrO}_{2}$ phase and the $\mathrm{Al}_{2} \mathrm{O}_{3}$ phase, respectively.
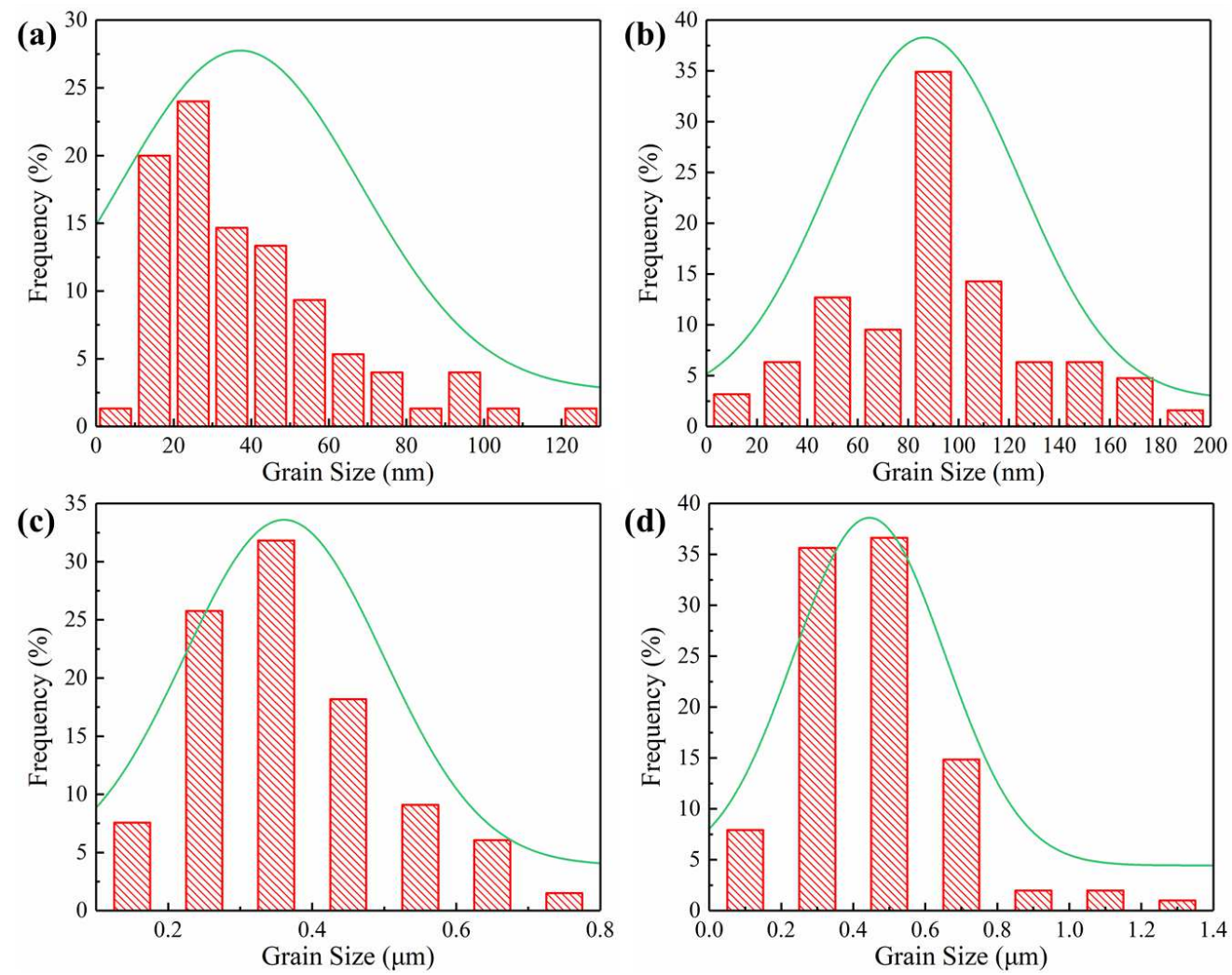

Fig. 4 The size distribution of nano- $\mathrm{ZrO}_{2}$ grains in the $\mathrm{Al}_{2} \mathrm{O}_{3}$ grains (a), nano- $\mathrm{Y}_{4} \mathrm{Al}_{2} \mathrm{O}_{9}$ grains in the $\mathrm{ZrO}_{2}$ grains (b), submicro- $\mathrm{ZrO}_{2}$ grains (c) and submicro- $\mathrm{Al}_{2} \mathrm{O}_{3}$ grains (d) in Fig. 3(b). The average grain size of these four grains is about $40 \mathrm{~nm}, 90 \mathrm{~nm}, 350 \mathrm{~nm}$ and $450 \mathrm{~nm}$, respectively. 

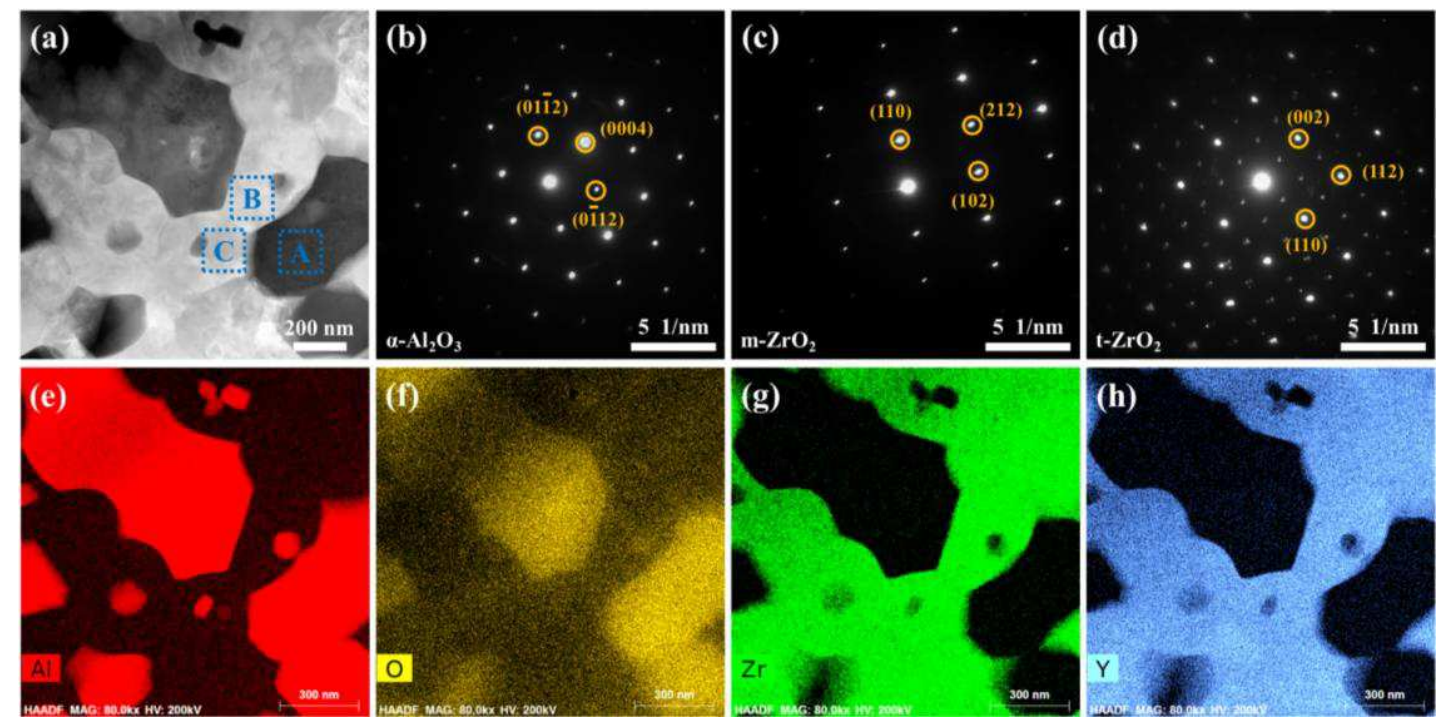

Fig. 5 (a) Cross-sectional STEM image of ATZ-1450. (b), (c) and (d) images show the selected area electron diffraction (SAED) of regions A, B, and C in Fig. (a). (e), (f), (g) and (h): The STEM-EDX elemental mappings show the distribution of $\mathrm{Al}, \mathrm{O}, \mathrm{Zr}$ and $\mathrm{Y}$ elements, respectively.
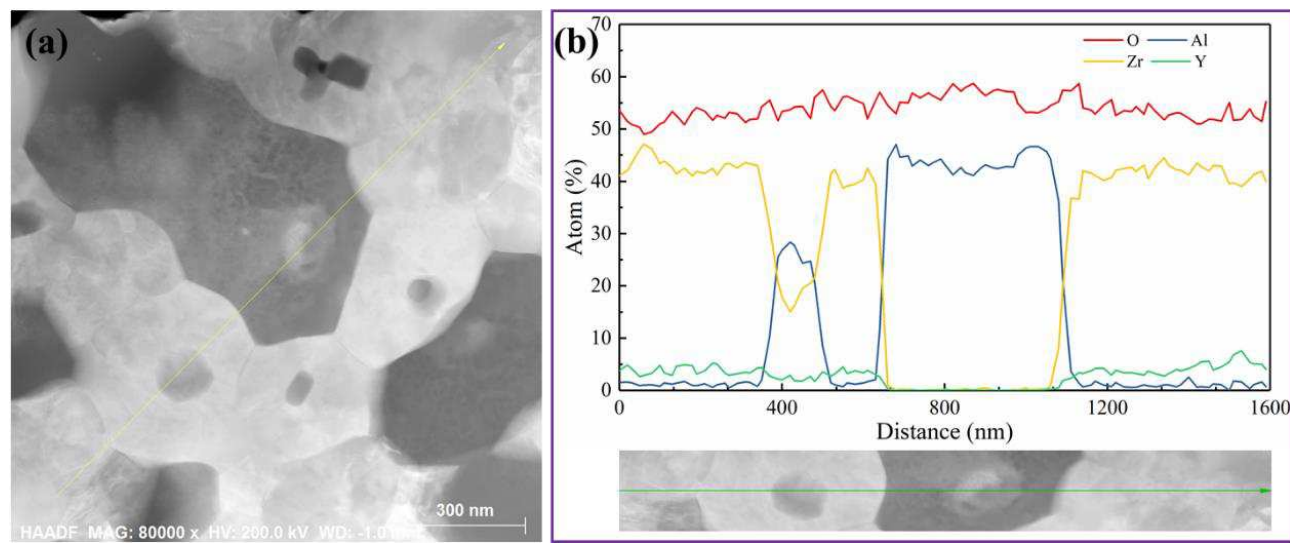

Fig. 6 (a) STEM image of ATZ-1450. (b) The STEM-EDX composition profile at the arrow position in Fig. (a) shows the distribution of $\mathrm{Al}, \mathrm{O}, \mathrm{Zr}$ and $\mathrm{Y}$ elements, respectively. 

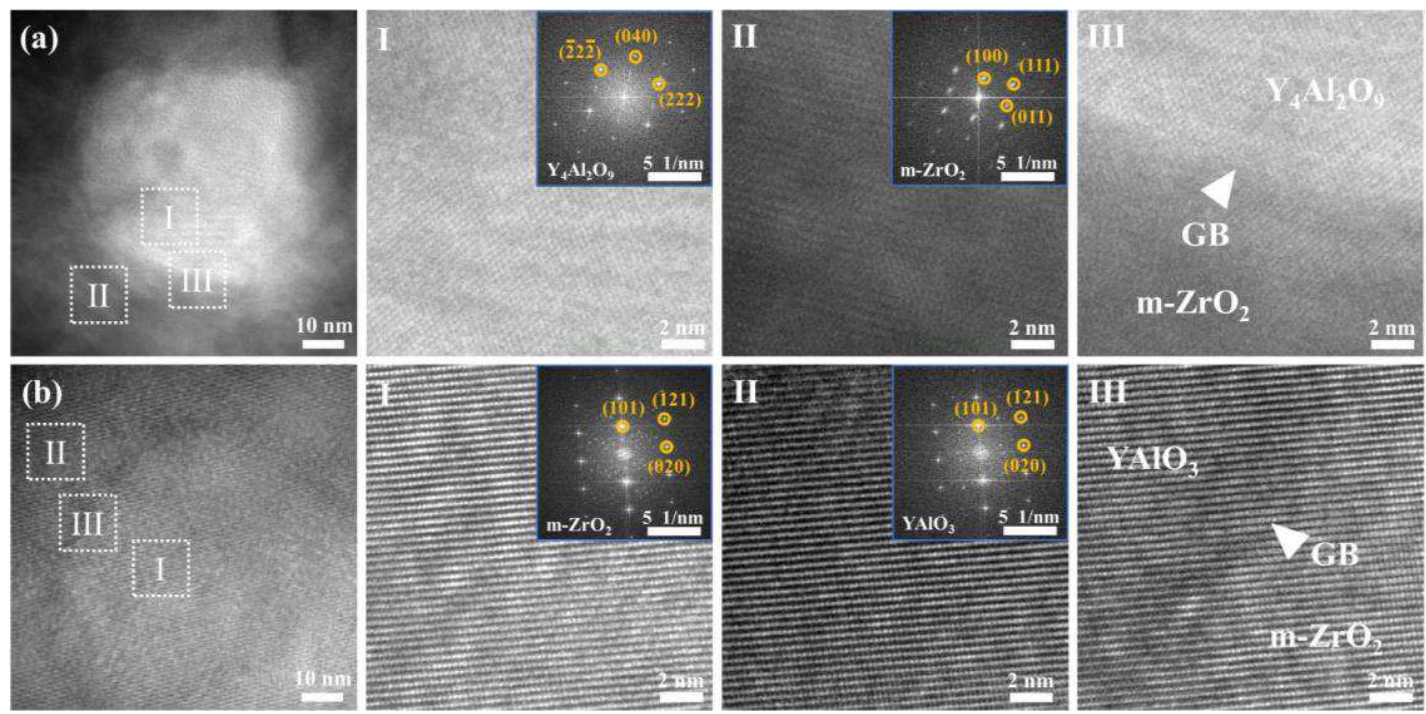

Fig. 7 HRTEM images of nanoparticles inside $\mathrm{ZrO}_{2}$ crystal (a) and $\mathrm{Al}_{2} \mathrm{O}_{3}$ crystal (b). I, II and III are enlarged images of different regions in Fig. (a) and Fig. (b), respectively. Insets in I and II are the corresponding FFT patterns.
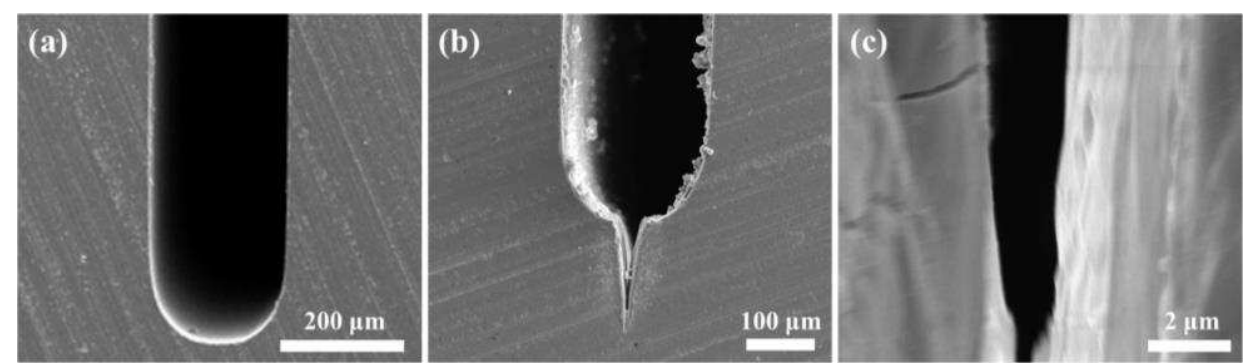

Fig. 8 (a) The SEM image of SENB sample showing that the root radius of U-notch is about $100 \mu \mathrm{m}$. (b) The SEM image of SEVNB sample showing that a femtosecond laser is used to cut an ultra-sharp Vnotch based on the U-notch. (c) An enlarged view of the V-notch with the tip radius of $\sim 0.6 \mu \mathrm{m}$ (much less than three times the grain size of ceramics [27-29]) indicating that this method can accurately measure the fracture toughness of ceramics.
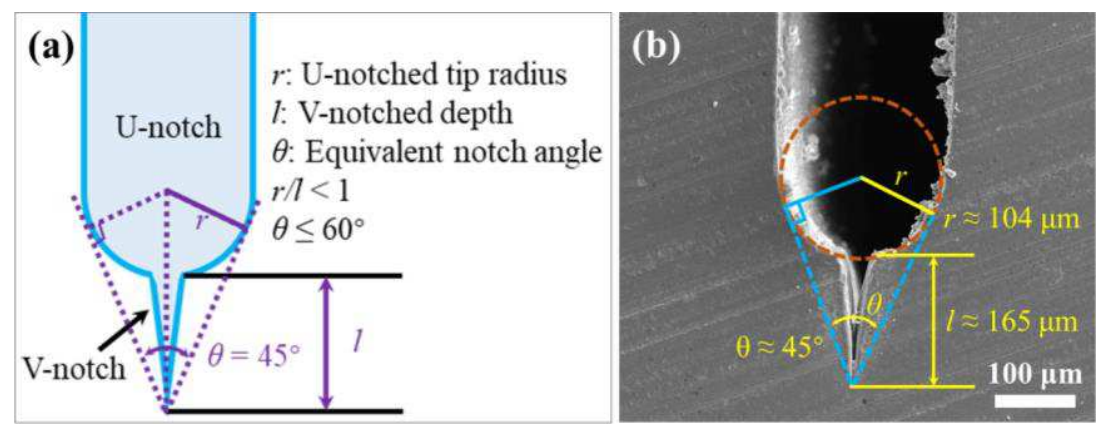

Fig. 9 (a) Schematic of the ultra-sharp V-notch with an equivalent notch angle $(\theta)$. The $\theta$ should be less than $60^{\circ}$ and the U-notched root radius $(r)$ should be less than the V-notched depth $(l)$. (b) The SEM image of ceramic bar with an ultra-sharp V-notch based on the U-notch. The U-notched root radius $(r)$, the $\mathrm{V}$-notched depth $(l)$ and the equivalent notch angle $(\theta)$ of SEVNB samples are about $104 \mu \mathrm{m}, 165 \mu \mathrm{m}$ and $45^{\circ}$, respectively. $r / l \approx 0.63<1$ and $45^{\circ}<60^{\circ}$, so SEVNB samples meet test standards. 

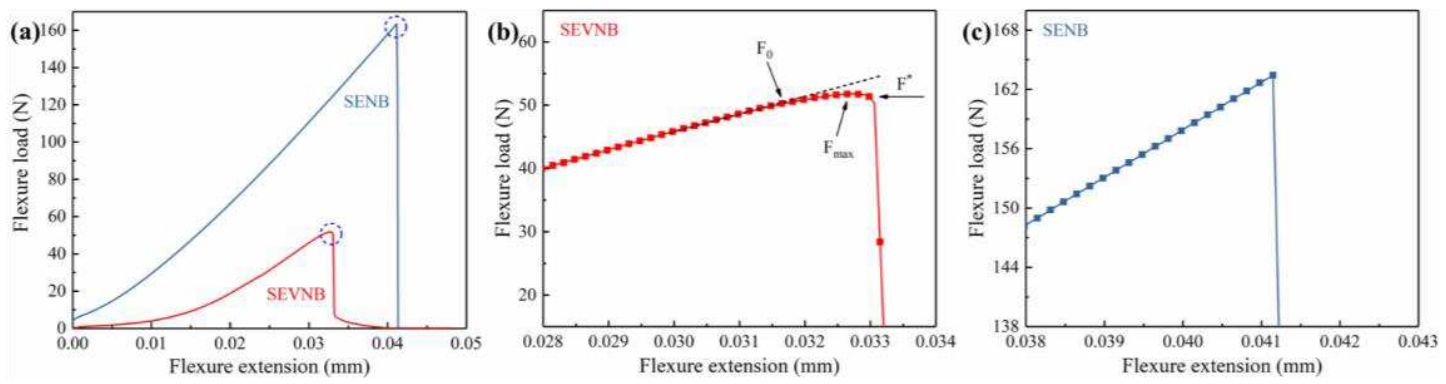

Fig. 10 (a) Stress-displacement graphs of SENB and SEVNB specimens. (b)and (c) are enlarged images of the dotted area in Fig. (a).
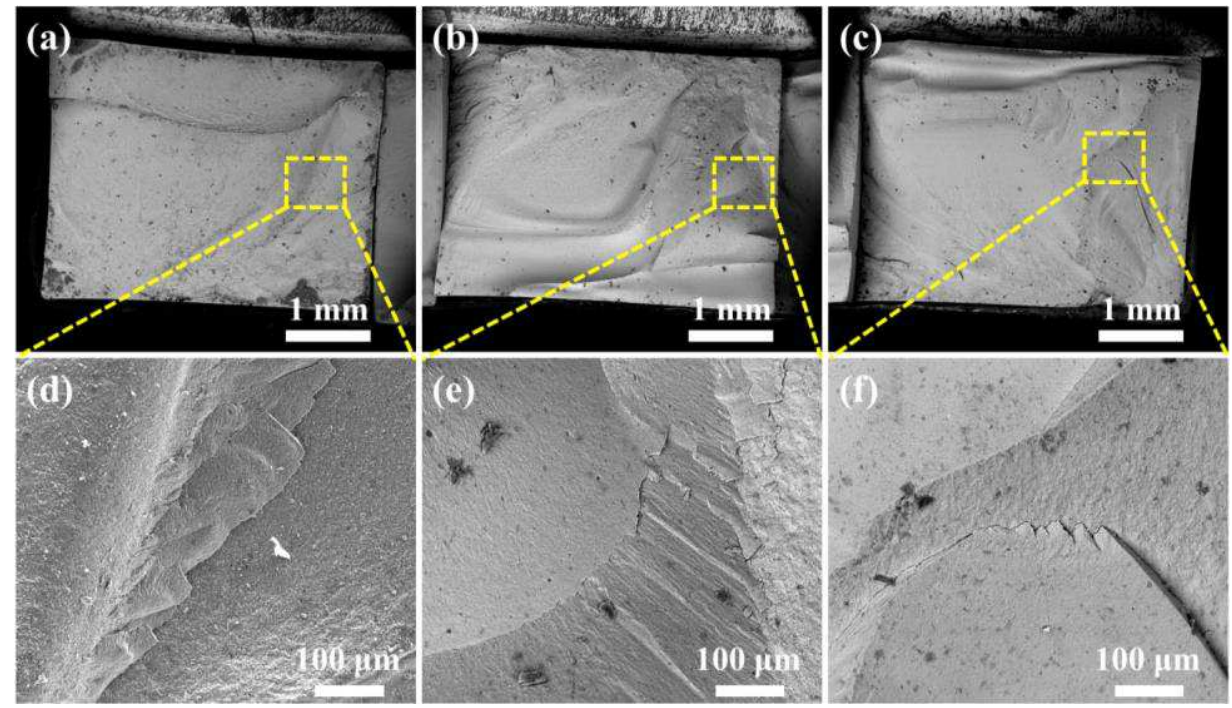

Fig. 11 The SEM images of fracture surface in the ATZ-1400 (a), ATZ-1450 (b) and ATZ-1500 (c). (d), (e) and (f) are the enlarged images of the dashed area in Figs. (a), (b) and (c).
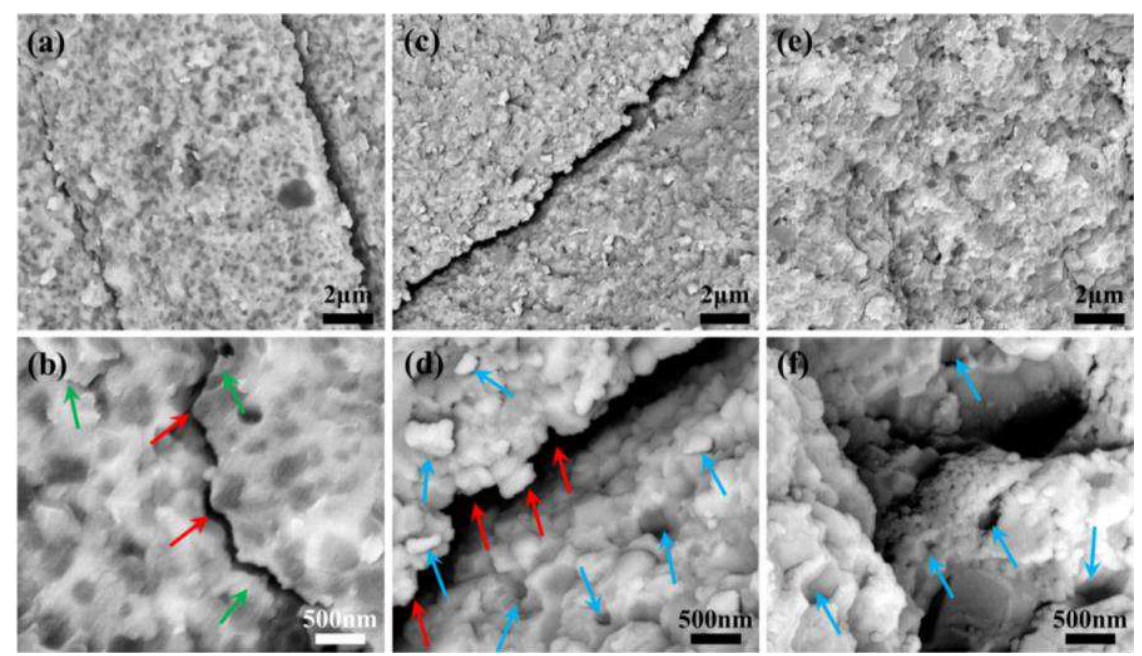

Fig. 12 (a) and (b): The BSE images of fracture surface in the ATZ-1400. (c) and (d): The SEM images of fracture surface in the ATZ-1450. (e) and (f): The SEM images of fracture surface in the ATZ-1500. 

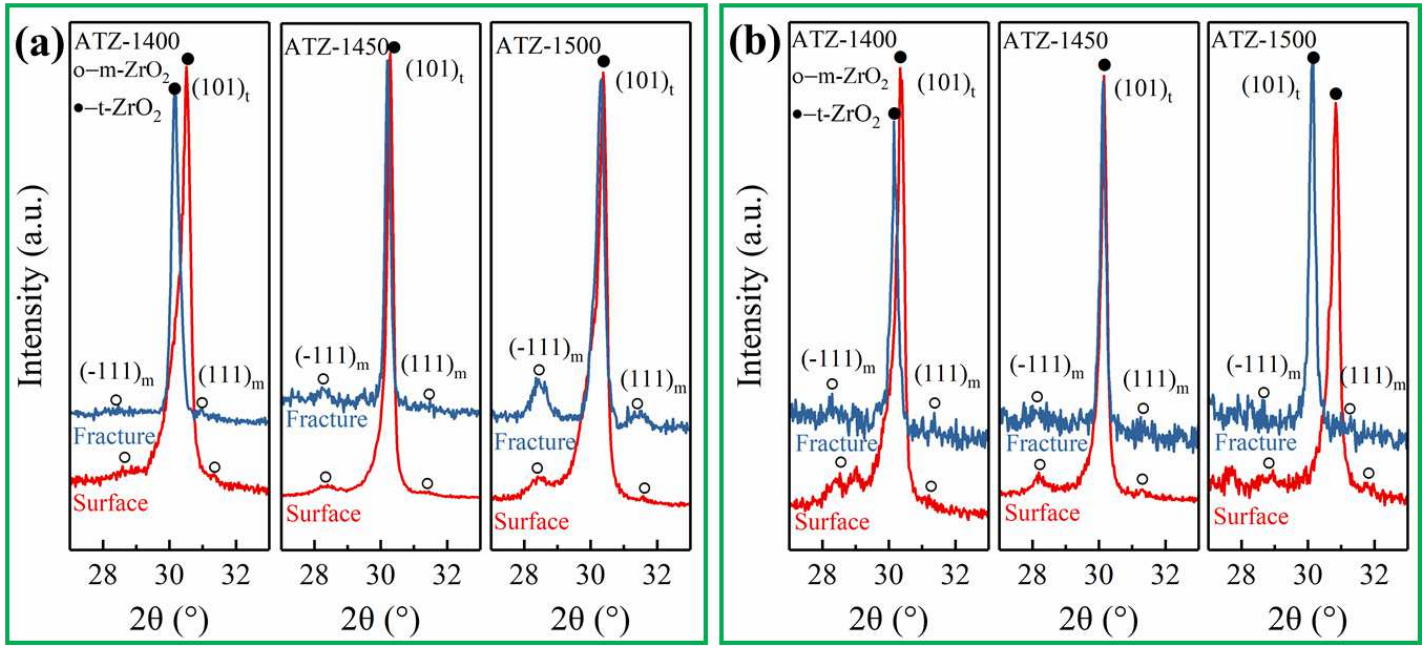

Fig. 13 The XRD analysis of $(101)_{\mathrm{t}},(\overline{1} 11)_{\mathrm{m}}$ and $(111)_{\mathrm{m}}$ crystal planes on fracture and surface of SENB (a) and SEVNB (b) samples.

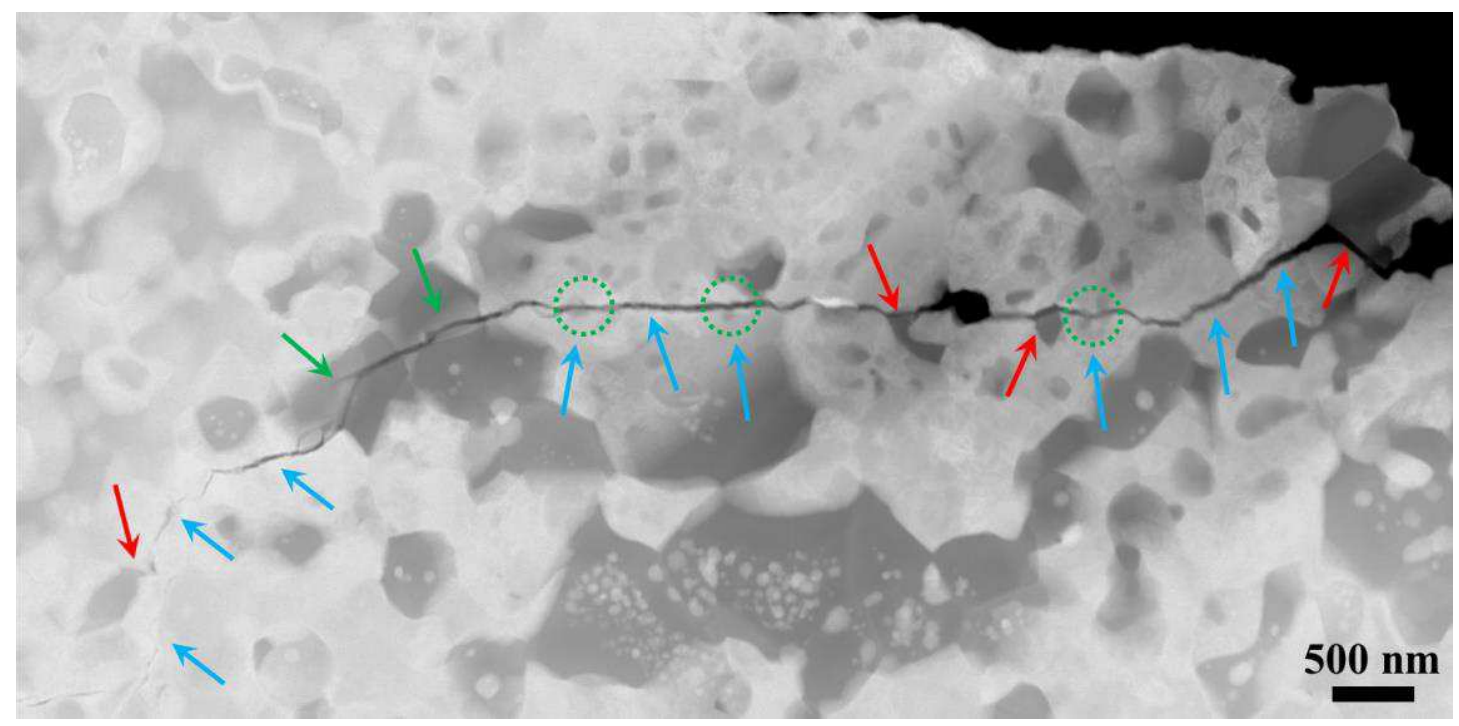

Fig. 14 (a) Cross-sectional STEM image of microcrack growth in ATZ-1450. The red and green arrows show green intergranular and transgranular fracture of $\mathrm{Al}_{2} \mathrm{O}_{3}$ grains, respectively. The blue arrows represent the transcrystalline fracture of $\mathrm{ZrO}_{2}$, and the circled areas indicate that the nanoparticles inside the $\mathrm{ZrO}_{2}$ grains promote crack deflection. 


\section{Table captions:}

Table 1 The lattice parameters and the unit cell volume of $\mathrm{t}-\mathrm{ZrO}_{2}$ measured by XRD. Table 2 The phase content (Semi-quantitative calculation), crystallinity and average grain size obtained from the XRD pattern.

Table 3 Comparison of flexural strength $(\sigma)$, Vickers hardness $\left(H_{v}\right)$ and relative density of ATZ.

Table 4 Comparison of fracture toughness $\left(K_{I c}\right)$ of ATZ tested by IM, SENB and SEVNB methods.

Table 5 The percentage of $K_{I c}$ overestimated by IM and SENB methods in ATZ compared with SEVNB. 
Table 1 The lattice parameters and the unit cell volume of $\mathrm{t}-\mathrm{ZrO}_{2}$ measured by XRD.

\begin{tabular}{ccccc}
\hline Component & \multicolumn{3}{c}{ Lattice parameters $(\AA)$} & $\begin{array}{c}\text { Unit cell volume } \\
\left(\AA^{3}\right)\end{array}$ \\
\cline { 2 - 4 } & $\mathrm{a}$ & $\mathrm{b}$ & $\mathrm{c}$ & 67.1536 \\
\hline $\mathrm{PDF} \# 83-0113$ & 3.6008 & 3.6008 & 5.1793 & \\
$\mathrm{Zr}_{0.963} \mathrm{Y}_{0.037} \mathrm{O}_{1.982}$ & & & & 66.6708 \\
Fine Powder & 3.5989 & 3.5989 & 5.1475 & 66.7204 \\
Coarse Powder & 3.5987 & 3.5987 & 5.1519 & \\
\hline
\end{tabular}

Table 2 The phase content (Semi-quantitative calculation), crystallinity and average grain size obtained from the XRD pattern.

\begin{tabular}{|c|c|c|c|c|c|c|c|}
\hline \multirow[b]{2}{*}{ Powder } & \multicolumn{5}{|c|}{ Phase content (wt $\%$ ) } & \multirow{2}{*}{$\begin{array}{c}\text { Crystallinity } \\
(\%)\end{array}$} & \multirow{2}{*}{$\begin{array}{c}\text { Average } \\
\text { grain } \\
\text { size }(\mathrm{nm})\end{array}$} \\
\hline & $\mathrm{t}-\mathrm{ZrO}_{2}$ & $\mathrm{~m}-\mathrm{ZrO}_{2}$ & $\alpha-\mathrm{Al}_{2} \mathrm{O}_{3}$ & $\gamma-\mathrm{Al}_{2} \mathrm{O}_{3}$ & $\begin{array}{c}\mathrm{Y}_{4} \mathrm{Al}_{2} \mathrm{O}_{9} \\
(\mathrm{YAM})\end{array}$ & & \\
\hline Fine & 50.25 & 18.86 & 0.00 & 24.84 & 6.05 & 87.55 & 33.0 \\
\hline Coarse & 65.91 & 4.54 & 18.12 & 9.63 & 1.80 & 96.26 & 47.2 \\
\hline
\end{tabular}

Table 3 Comparison of flexural strength $(\sigma)$, Vickers hardness $\left(H_{v}\right)$ and relative density of ATZ.

\begin{tabular}{cccc}
\hline Sample & $\begin{array}{c}\text { Flexural strength } \\
(\sigma, \mathrm{MPa})\end{array}$ & $\begin{array}{c}\text { Vickers hardness } \\
\left(H_{v}, \mathrm{GPa}\right)\end{array}$ & $\begin{array}{c}\text { Relative density } \\
(\%)\end{array}$ \\
\hline ATZ-1400 & $883 \pm 76$ & $16.32 \pm 0.45$ & 99.31 \\
ATZ-1450 & $896 \pm 58$ & $15.78 \pm 0.30$ & 99.47 \\
ATZ-1500 & $857 \pm 81$ & $15.09 \pm 0.23$ & 99.63 \\
\hline
\end{tabular}

Table 4 Comparison of fracture toughness $\left(K_{I c}\right)$ of ATZ tested by IM, SENB and SEVNB methods.

\begin{tabular}{cccccc}
\hline \multirow{2}{*}{ Sample } & \multicolumn{2}{c}{ Fracture toughness $\left(K_{I c}, \mathrm{MPa} \cdot \mathrm{m}^{1 / 2}\right)$} & $\mathrm{t}-\mathrm{m}$ phase transformation $(\mathrm{vol} \%)$ \\
\cline { 2 - 6 } & $\mathrm{IM}$ & $\begin{array}{c}\mathrm{SENB} \\
(r \approx 100 \mu \mathrm{m})\end{array}$ & $\begin{array}{c}\mathrm{SEVNB} \\
(r \approx 0.6 \mu \mathrm{m})\end{array}$ & SENB & SEVNB \\
\hline ATZ-1400 & $7.18 \pm 0.31$ & $13.82 \pm 0.55$ & $5.53 \pm 0.15$ & 9.72 & 6.04 \\
ATZ-1450 & $6.97 \pm 0.24$ & $13.31 \pm 0.45$ & $5.68 \pm 0.17$ & 10.58 & 4.47 \\
ATZ-1500 & $7.05 \pm 0.27$ & $12.68 \pm 0.52$ & $5.49 \pm 0.08$ & 13.45 & 3.15 \\
\hline
\end{tabular}


Table 5 The percentage of $K_{I c}$ overestimated by IM and SENB methods in ATZ compared with SEVNB.

\begin{tabular}{ccccc}
\hline \multirow{2}{*}{ Method } & \multicolumn{4}{c}{ Overestimated percentage of $K_{I c}(\%)$} \\
\cline { 2 - 5 } & ATZ-1400 & ATZ-1450 & ATZ-1500 & Average \\
\hline IM & 29.84 & 22.71 & 28.42 & 26.99 \\
SENB & 149.91 & 134.33 & 130.97 & 138.40 \\
\hline
\end{tabular}


Figures
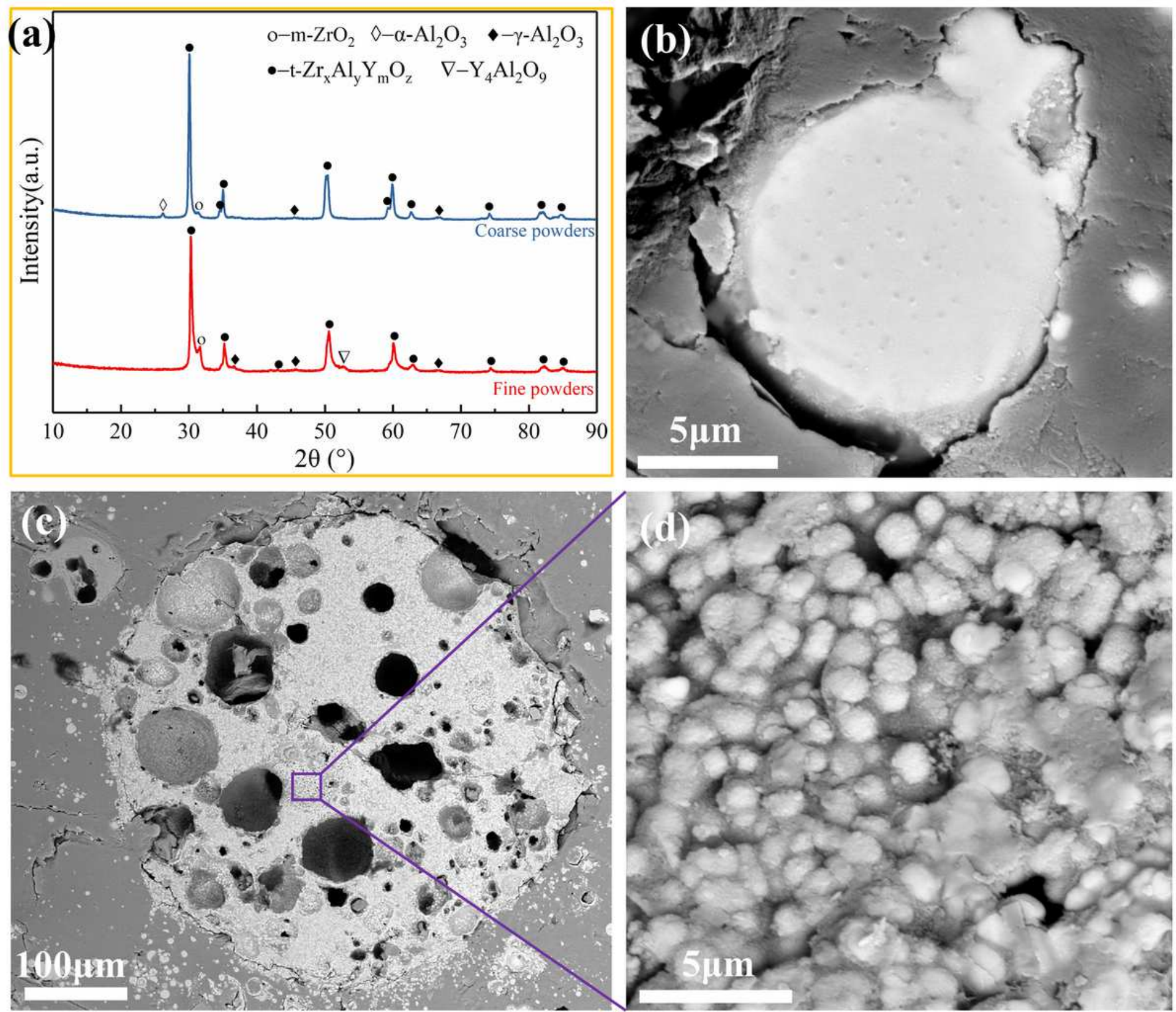

Figure 1

(a) XRD patterns of AZSSP. The BSE images of cross-sections of fine powders (b) and coarse powders (c). (d) An enlarged view of the box area in Fig. (c). The light phase represents the ZrO2 phase, and the dark phase represents the Al2O3 phase. 

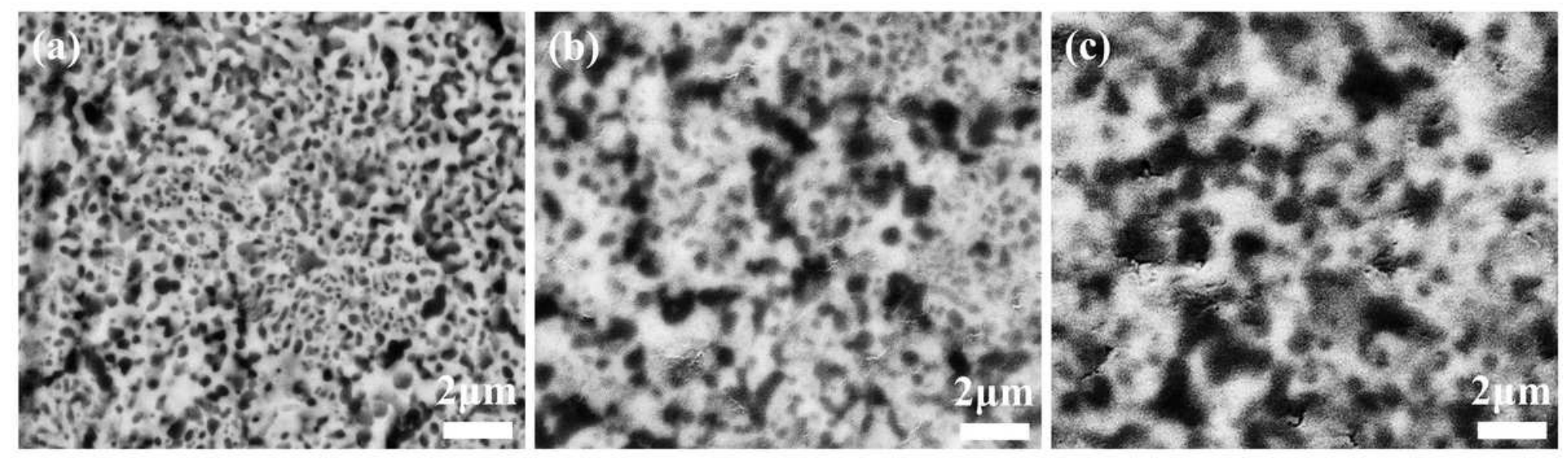

\section{Figure 2}

The cross-sectional BSE pictures of ATZ-1400, ATZ-1450 and ATZ-1500. The bright phase and the dark phase represent the ZrO2 phase and the Al203 phase, respectively.
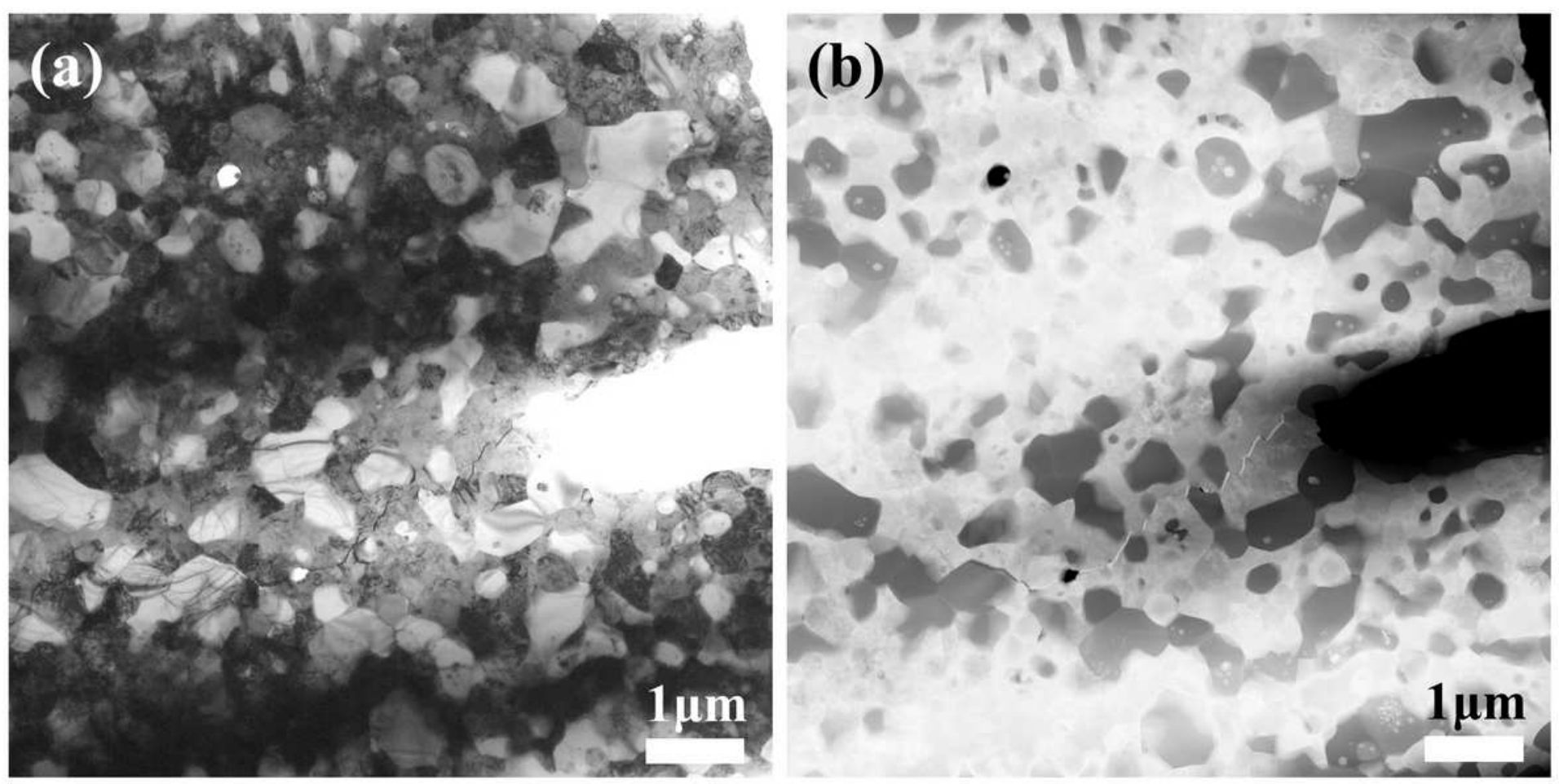

\section{Figure 3}

Cross-sectional TEM (a) and STEM (b) images of ATZ-1450. The bright phase and the dark phase in Fig. (b) represent the $\mathrm{ZrO} 2$ phase and the Al2O3 phase, respectively. 

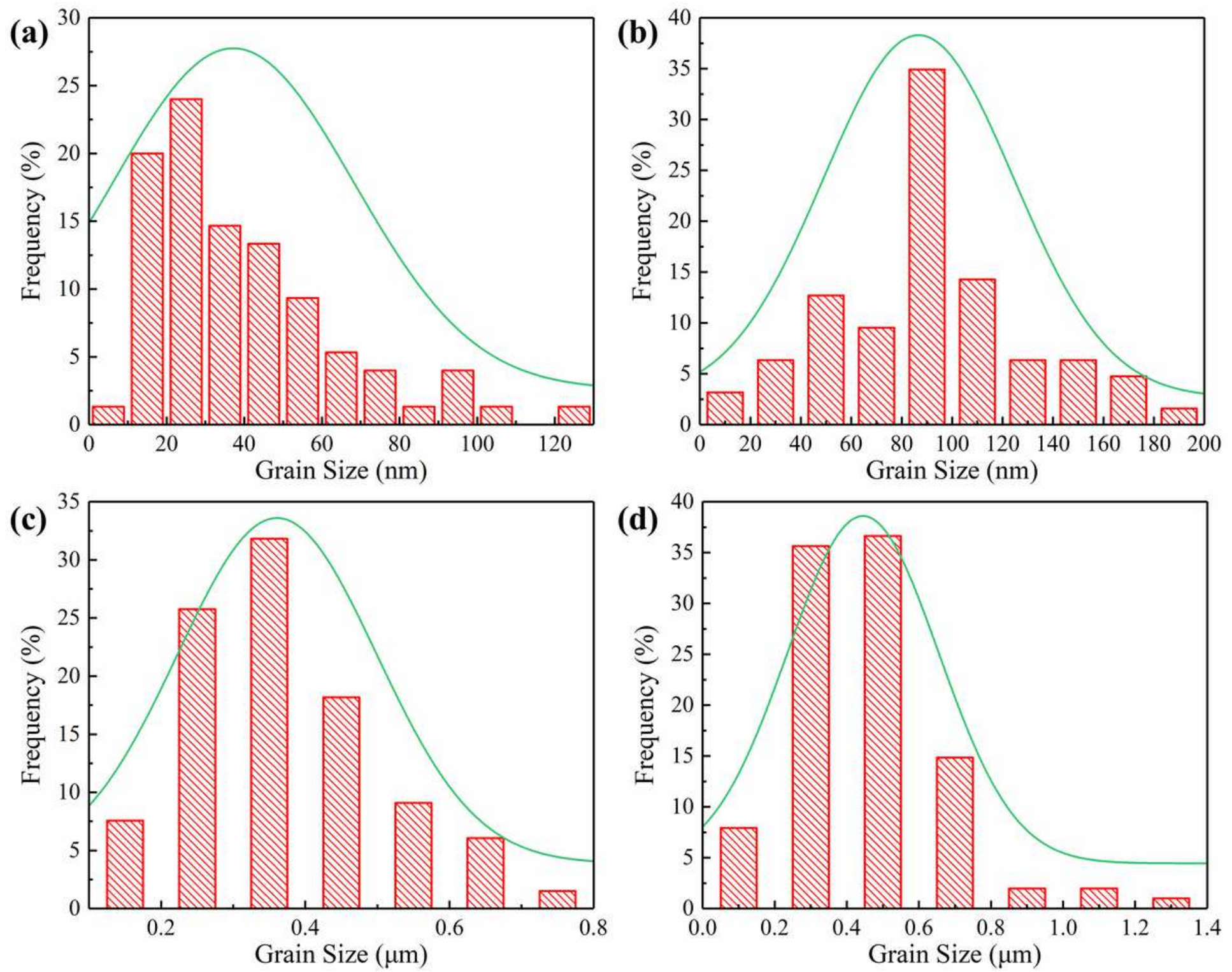

Figure 4

The size distribution of nano-ZrO2 grains in the Al2O3 grains (a), nano-Y4Al2O9 grains in the ZrO2 grains (b), submicro-ZrO2 grains (c) and submicro-Al2O3 grains (d) in Fig. 3(b). The average grain size of these four grains is about $40 \mathrm{~nm}, 90 \mathrm{~nm}, 350 \mathrm{~nm}$ and $450 \mathrm{~nm}$, respectively. 

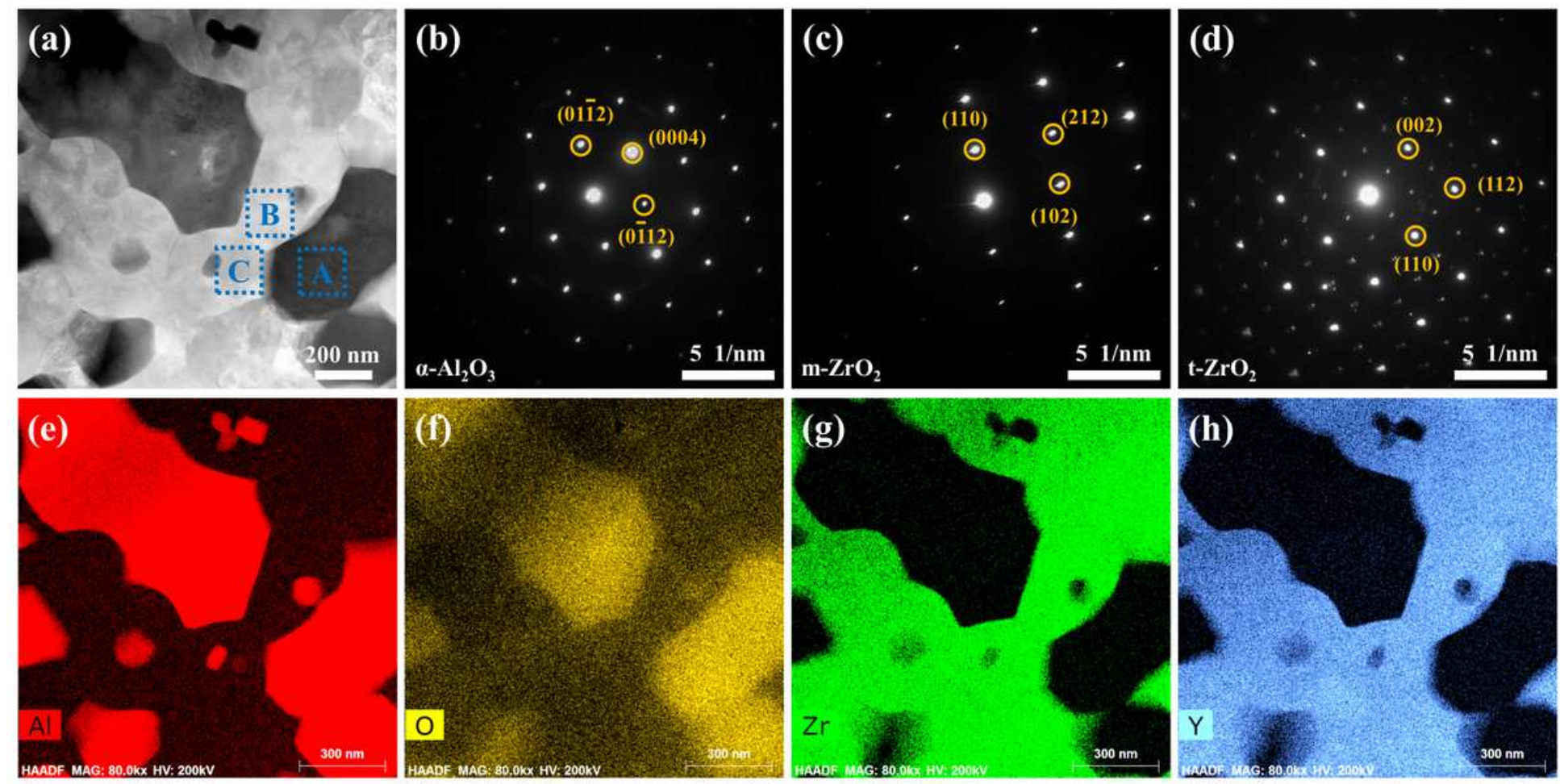

\section{Figure 5}

(a) Cross-sectional STEM image of ATZ-1450. (b), (c) and (d) images show the selected area electron diffraction (SAED) of regions A, B, and C in Fig. (a). (e), (f), (g) and (h): The STEM-EDX elemental mappings show the distribution of $\mathrm{Al}, \mathrm{O}, \mathrm{Zr}$ and $\mathrm{Y}$ elements, respectively.
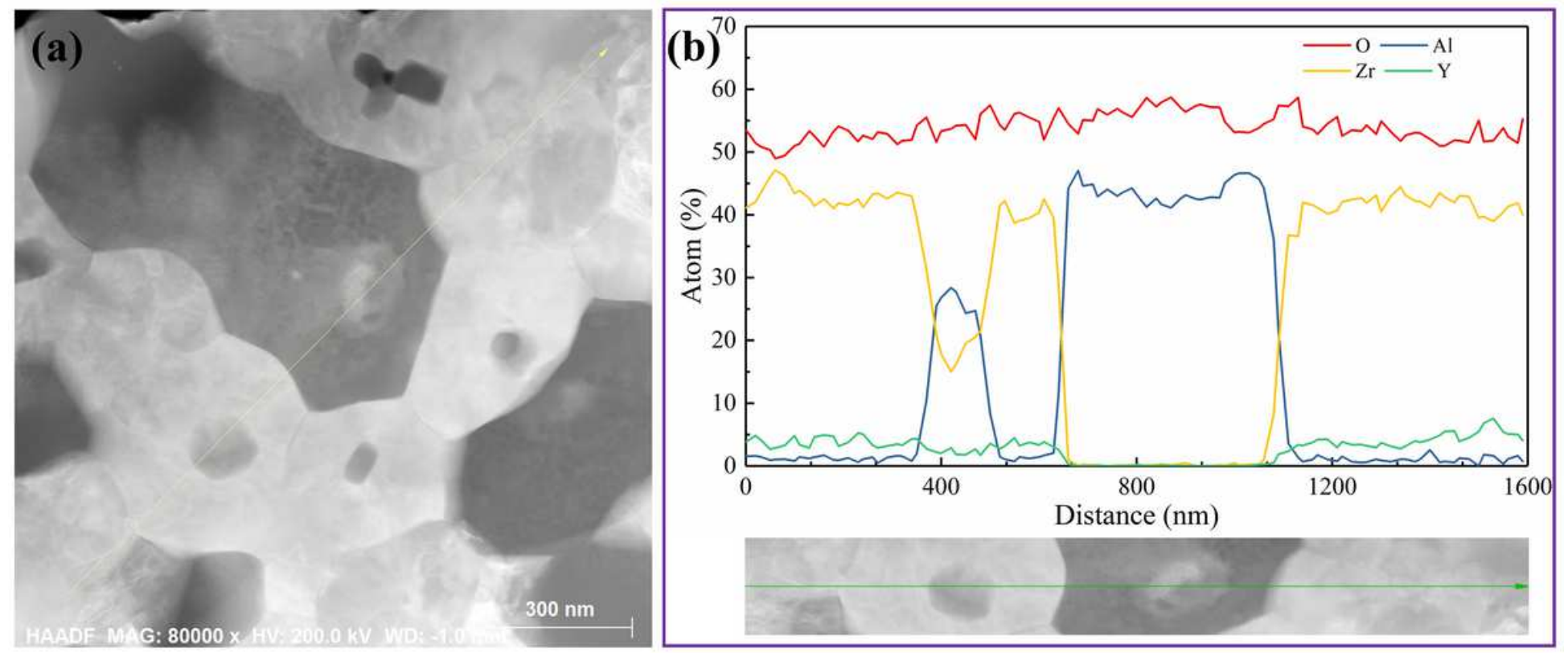

\section{Figure 6}

(a) STEM image of ATZ-1450. (b) The STEM-EDX composition profile at the arrow position in Fig. (a) shows the distribution of $\mathrm{Al}, \mathrm{O}, \mathrm{Zr}$ and $\mathrm{Y}$ elements, respectively. 

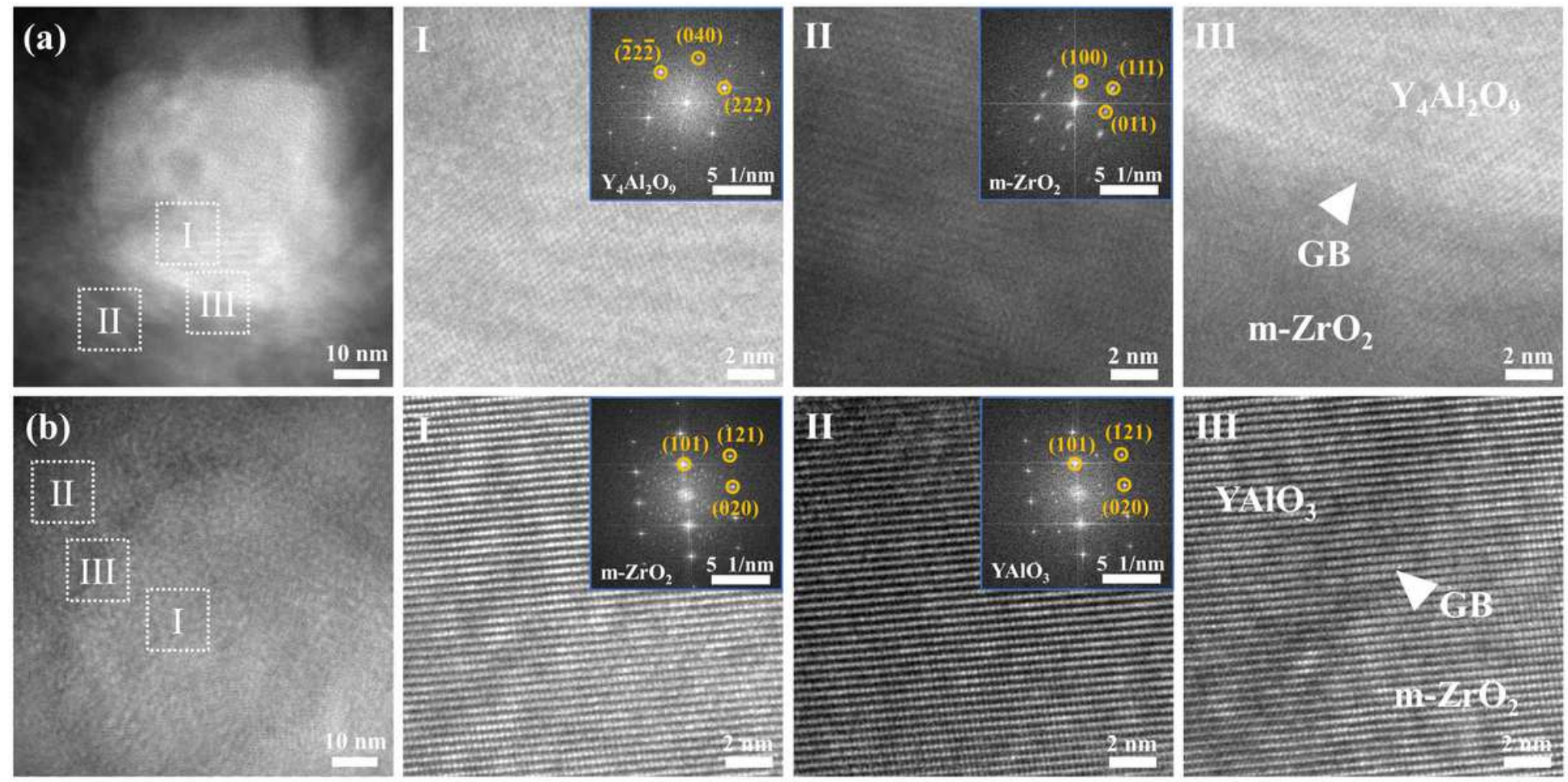

\section{Figure 7}

HRTEM images of nanoparticles inside ZrO2 crystal (a) and Al2O3 crystal (b). I, II and III are enlarged images of different regions in Fig. (a) and Fig. (b), respectively. Insets in I and II are the corresponding FFT patterns.
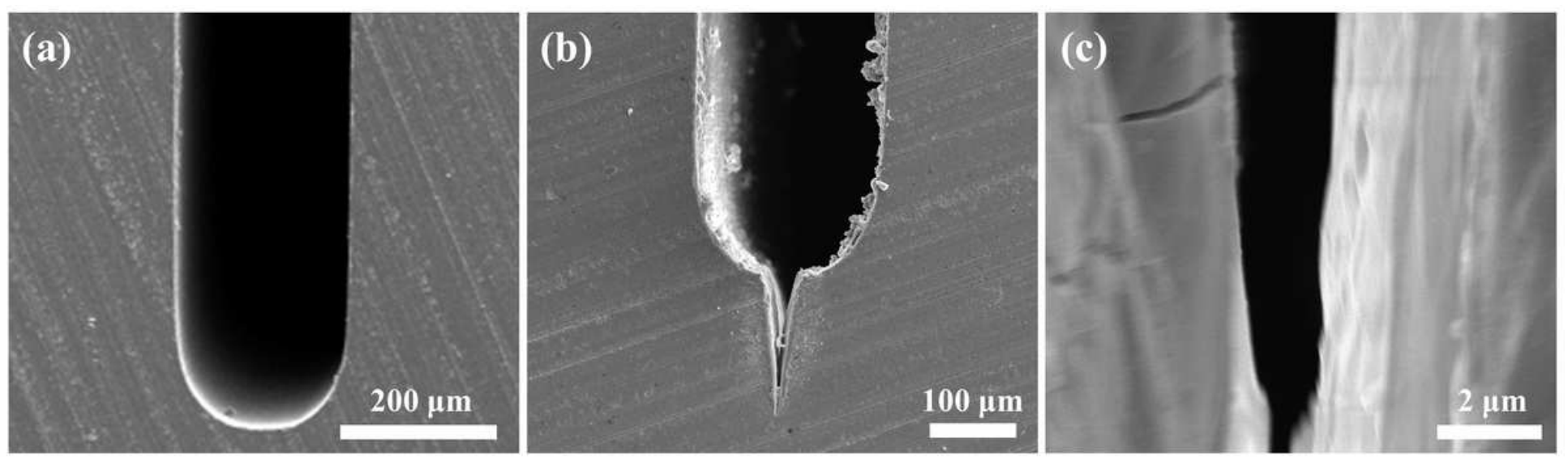

\section{Figure 8}

(a) The SEM image of SENB sample showing that the root radius of U-notch is about $100 \mu \mathrm{m}$. (b) The SEM image of SEVNB sample showing that a femtosecond laser is used to cut an ultra-sharp V-notch based on the U-notch. (c) An enlarged view of the V-notch with the tip radius of $\sim 0.6 \mu \mathrm{m}$ (much less than three times the grain size of ceramics [27-29]) indicating that this method can accurately measure the fracture toughness of ceramics. 

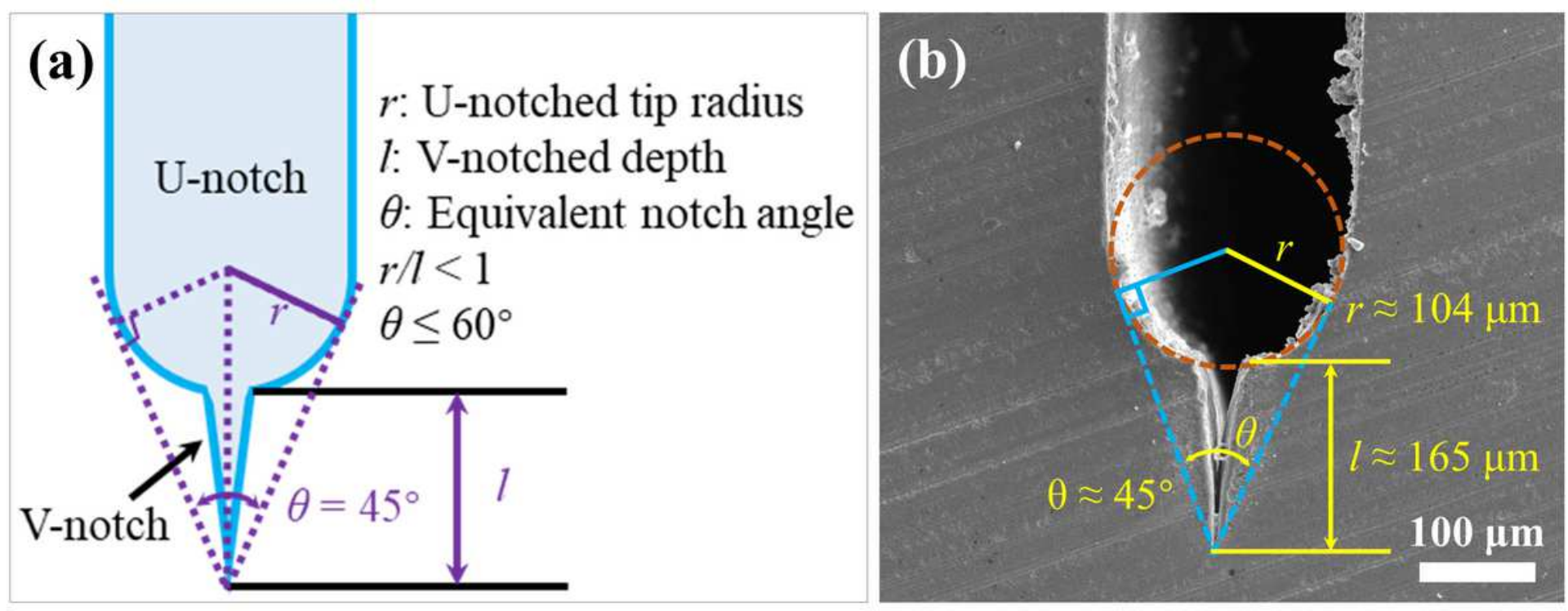

\section{Figure 9}

(a) Schematic of the ultra-sharp V-notch with an equivalent notch angle $(\theta)$. The $\theta$ should be less than 60 ${ }^{\circ}$ and the U-notched root radius ( $r$ ) should be less than the V-notched depth (I). (b) The SEM image of ceramic bar with an ultra-sharp V-notch based on the U-notch. The U-notched root radius ( $r$ ), the Vnotched depth (I) and the equivalent notch angle $(\theta)$ of SEVNB samples are about $104 \mu \mathrm{m}, 165 \mu \mathrm{m}$ and $45^{\circ}$, respectively. $\mathrm{r} / \mathrm{I} \approx 0.63<1$ and $45^{\circ}<60^{\circ}$, so SEVNB samples meet test standards.
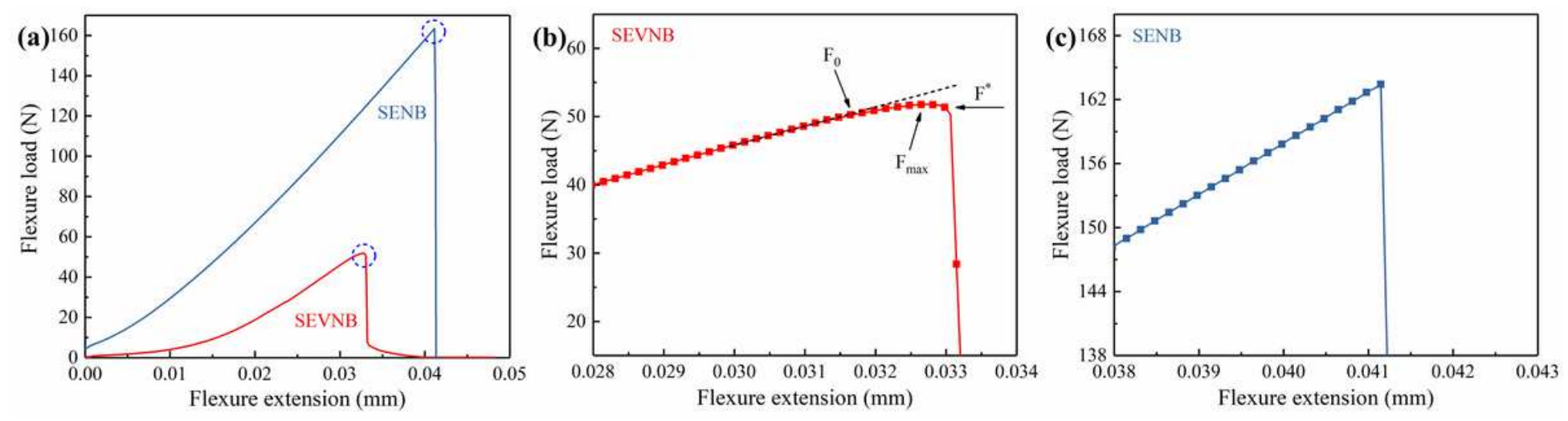

\section{Figure 10}

(a) Stress-displacement graphs of SENB and SEVNB specimens. (b)and (c) are enlarged images of the dotted area in Fig. (a). 

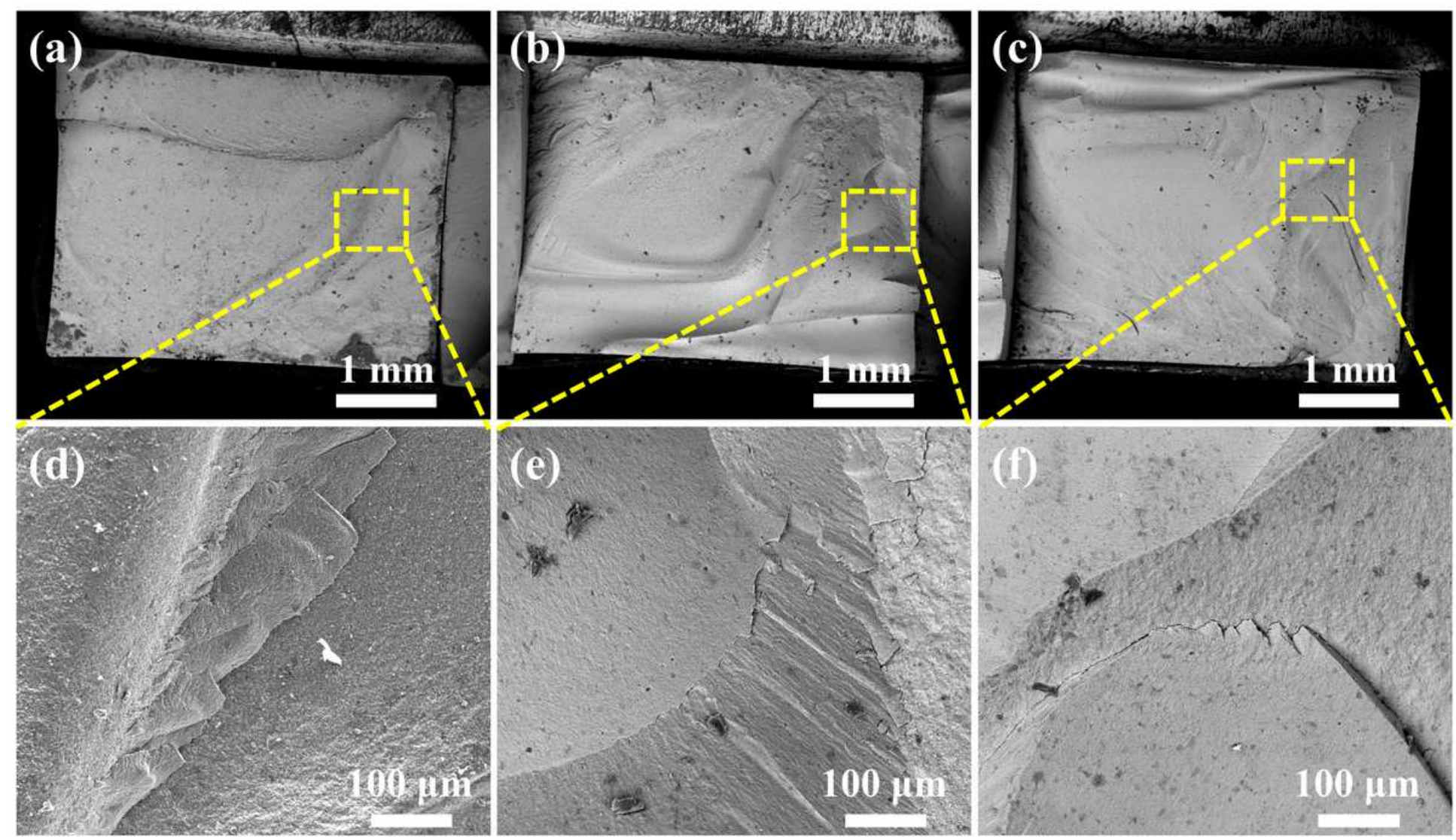

Figure 11

The SEM images of fracture surface in the ATZ-1400 (a), ATZ-1450 (b) and ATZ-1500 (c). (d), (e) and (f) are the enlarged images of the dashed area in Figs. (a), (b) and (c). 

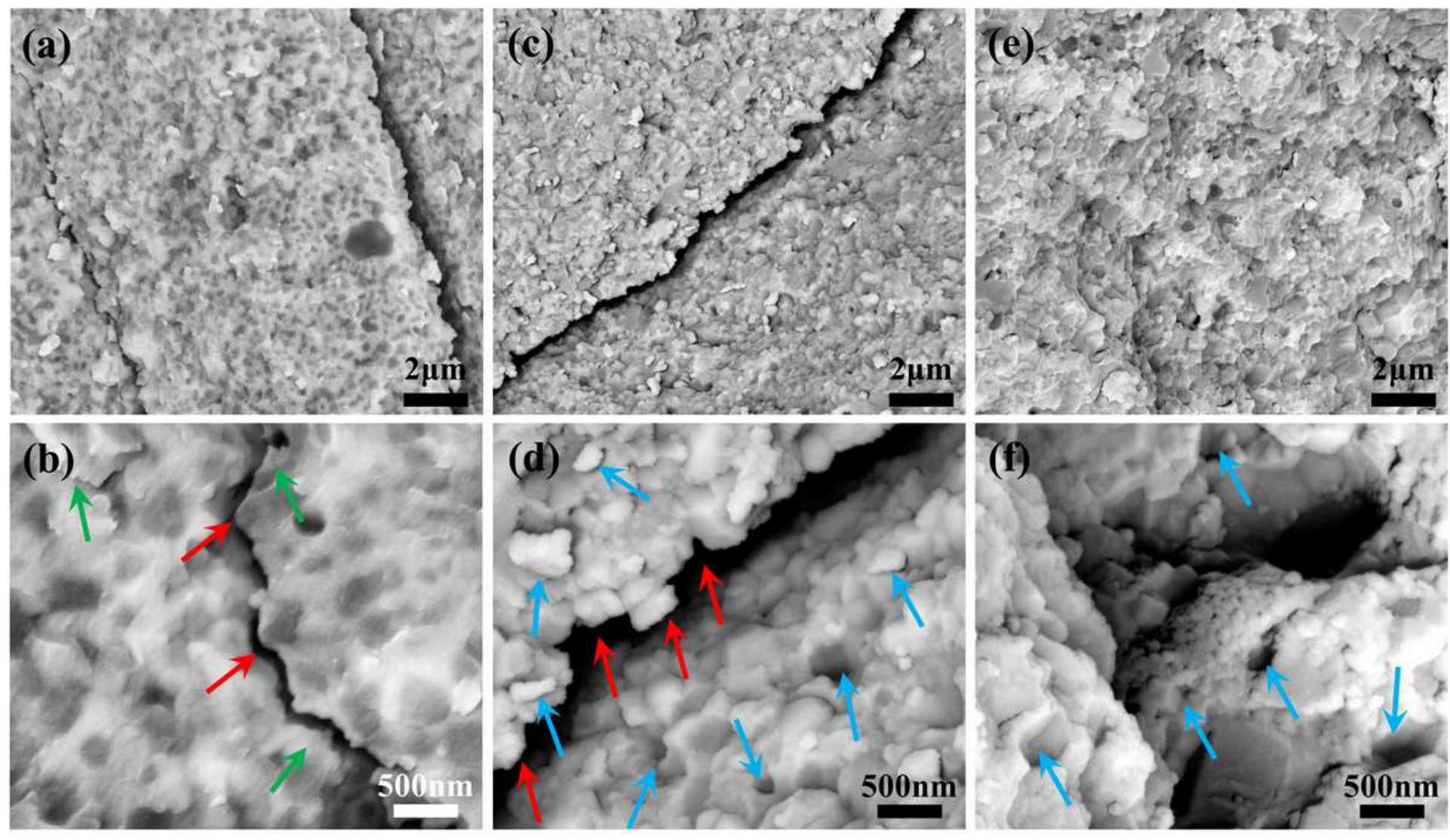

Figure 12

(a) and (b): The BSE images of fracture surface in the ATZ-1400. (c) and (d): The SEM images of fracture surface in the ATZ-1450. (e) and (f): The SEM images of fracture surface in the ATZ-1500.
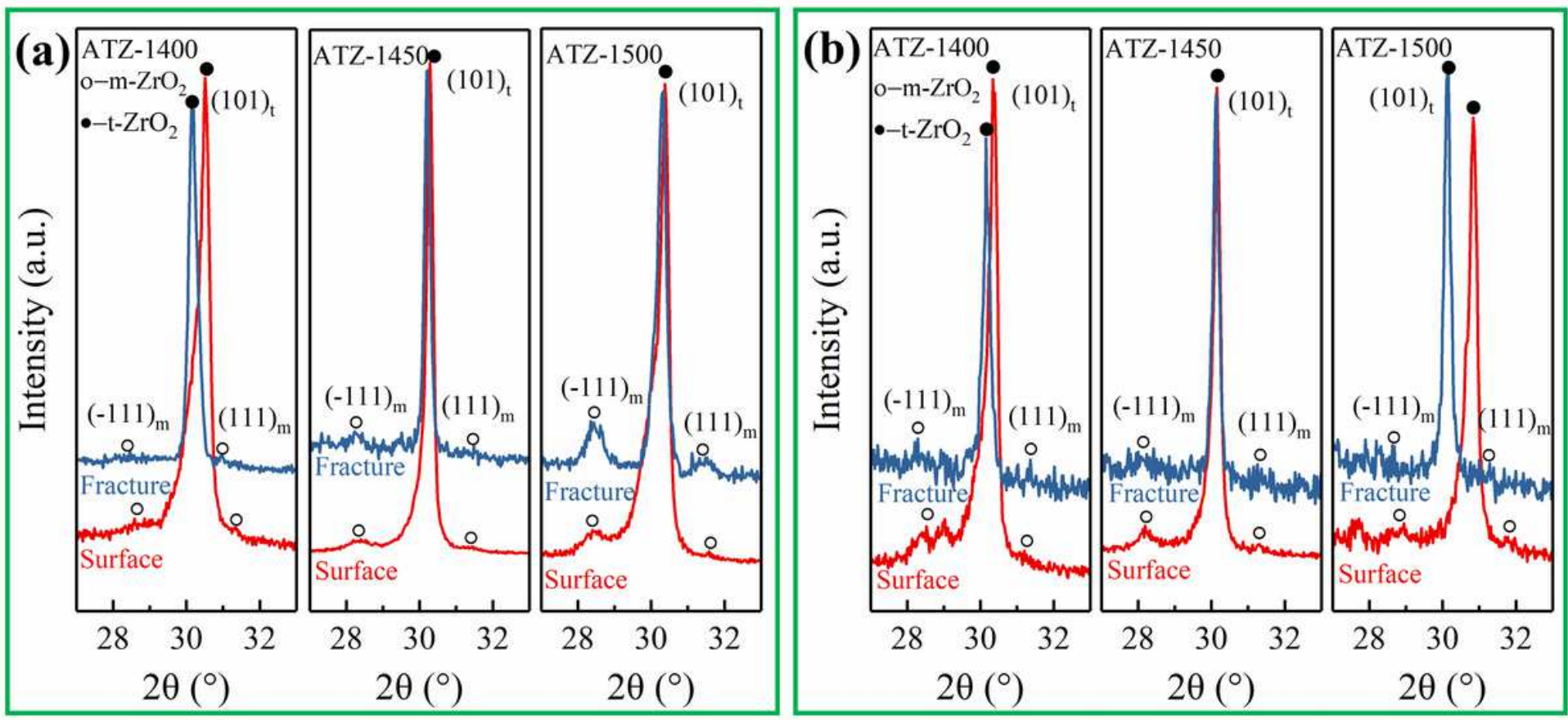

Figure 13 
The XRD analysis of (101)t, ( )m and (111)m crystal planes on fracture and surface of SENB (a) and SEVNB (b) samples.

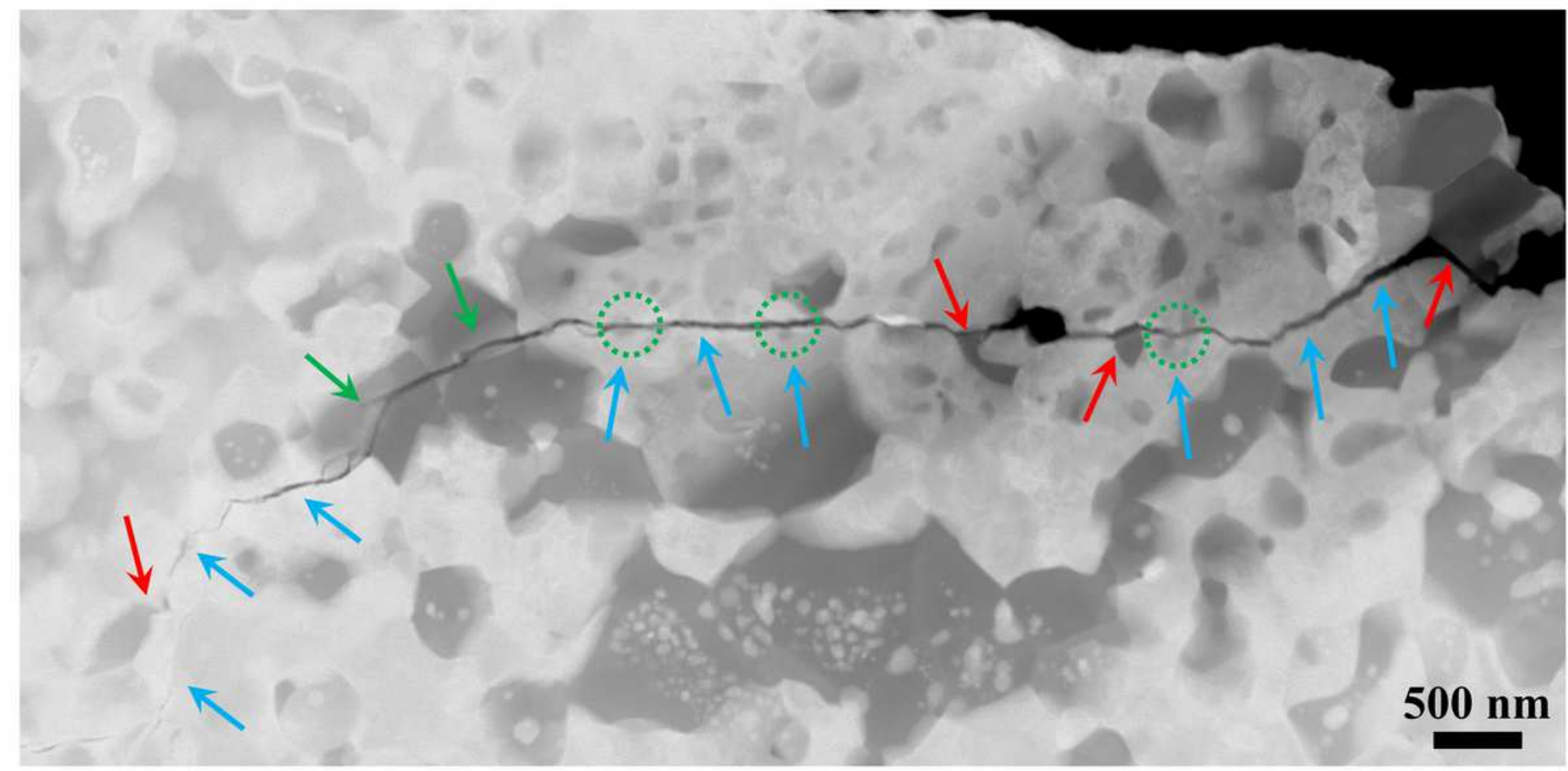

\section{Figure 14}

(a) Cross-sectional STEM image of microcrack growth in ATZ-1450. The red and green arrows show green intergranular and transgranular fracture of Al2O3 grains, respectively. The blue arrows represent the transcrystalline fracture of $\mathrm{ZrO} 2$, and the circled areas indicate that the nanoparticles inside the $\mathrm{ZrO} 2$ grains promote crack deflection.

\section{Supplementary Files}

This is a list of supplementary files associated with this preprint. Click to download.

- SupplementaryInformation.docx 